\title{
LA CRISIS AGRARIA DE FINALES DEL SIGLO XIX EN MALAGA*
}

\author{
CARMELO PELLEJERO MARTINEZ \\ Universidad de Málaga
}

Recientemente, G. Tortella ha. recordado el acierto del llamado enfoque geográfico-ecológico de la escuela histórica francesa, en general, y de F. Braudel en particular ${ }^{1}$. Según el profesor Tortella, si queremos comprender el problema del atraso económico de la España contemporánea, es necesario que entronquemos este caso particular dentro del más general de la región mediterránea y no estudiarlo como un fenómeno aislado ${ }^{2}$.

El objetivo de este artículo es, en primer lugar, ofrecer una visión de la crisis sufrida por la economía agraria de una provincia andaluza a finales del siglo XIX, concretándonos en los tres cultivos mediterráneos - cereal, olivar y vid- que, tal vez, protagonizaron de modo más destacado dicha crisis. En segundo lugar, el presente trabajo ha buscado un enfoque geográfico provincial que, en el caso de Málaga, permite observar características generales de una economía mediterránea $y$, a la vez, presenta particularidades conocidas, como la depresión vitivinícola del último veintenio del siglo xix. Por último, se intenta proporcionar una imagen cuantitativa de la agricultura malagueña, en los tres cultivos mencionados, con datos de superficie y rendimientos.

\section{LA CRISIS AGRICOLA Y PECUARIA}

Tras unos años de expansión, la agricultura del continente europeo se vio inmersa en una profunda crisis a partir de mediados de la década de 1870-

* Quiero agradecer a Pedro Tedde de Lorca tanto su paciencia a la hora de leer y discutir diversas versiones de este artículo como sus útiles comentarios, los cuales han contribuido a mejorarlo sustancialmente. También doy las gracias a J. F. Zambrana por su generosa ayuda y por el estímulo que me ha prestado, así como a Antonio $\mathrm{M}$. Bernal, Aurora Gámez y Vicente Pérez Moreda por sus excelentes consejos.

1 Tortella (1981), p. 16. Como prueba del interés por promover un enfoque comparativo en el estudio de la Historia Económica de la Europa del Sur, hay que mencionar el encuentro «Problemas históricos del desarrollo económico en la Europa del Sur: Italia, España y Portugal entre las décadas de 1830 y 1930 ", celebrado en Sevilla en el mes de octubre de 1984.

2 Tortella (1981), p. 15. 
$1880^{3}$. Como es sabido, en estos años comienzan a llegar a Europa, y a precios muy inferiores a los registrados en el viejo continente, toda una serie de productos agrícolas y ganaderos, especialmente trigo, procedentes de países como Estados Unidos de América, Canadá, Argentina, Rusia y la India, principalmente. Prueba evidente de la saturación sufrida por el mercado agrícola europeo es el hecho de que las exportaciones de trigo realizadas por los países anteriormente citados se multiplicaron por once entre 1850-1859 y final de siglo 4 .

Las causas que favorecieron la invasión de los mercados europeos fueron tanto el abaratamiento del transporte marítimo y ferroviario como que en los países ultramarinos la tierra fuera un bien casi ilimitado, barato y donde la mecanización era factible gracias al tamaño de las explotaciones y a la escasa fuerza de trabajo.

El efecto inmediato de esta situación fue la caída de las cotizaciones de las subsistencias afectadas, hecho que se mantuvo hasta finales de siglo. La conmoción sufrida por las agriculturas europeas ante la competencia foránea hizo que se adoptaran una serie de soluciones de distinta índole. Por una parte, hubo agriculturas que se enfrentaron a esa situación buscando obtener rendimientos medios iguales o superiores a los obtenidos por las agriculturas de las zonas fértiles alejadas. Así, se intentó introducir tecnología a través de la aplicación de maquinaria, se utilizaron abonos, se buscó una mayor especialización de la ganadería.

Por otro lado, hubo una serie de naciones que impidieron la entrada de productos extranjeros mediante una mayor protección arancelaria. Salvo Gran Bretaña, la mayoría de los países europeos adoptaron alguna que otra defensa proteccionista. En el norte de Europa se intentó que hubiera una combinación de medidas económicas con otras de carácter comercial y políticas proteccionistas. Fue en las naciones del sur del continente donde la protección arancelaria resultó más enérgica.

En toda Europa, el sector más afectado fue el cerealícola, registrándose, en líneas generales, una reducción de la superficie sembrada. Además del cereal, otros productos se vieron también involucrados en la depresión. El olivar lo hizo a partir de la década de $1870-1880$, como consecuencia de la competencia ejercida tanto por el petróleo como por los aceites vegetales y semillas oleaginosas llegadas a Europa de una forma masiva. La vid se vio inmer-

${ }^{3}$ De la extensa bibliografía existente sobre la evolución de la agricultura europea a lo largo del siglo pasado me parece interesante destacar: Abel (1973), D'Angiolini (1969), Guillén (1973), Pereira (1971), Luzzato (1963), Malenbaum (1953), Orwin y Whetman (1971), Perry (1974), Price (1983) y Tracy (1964).

4 Garrabou (1985), p. 143. 
sa algo más tarde, concretamente en los años noventa, a consecuencia de una sobreproducción.

La crisis persistió en Europa occidental hasta finales de la centuria pasada, ya que sólo a partir de 1896 se detectó una cierta recuperación de los precios. Se consiguió un incremento del rendimiento y un abaratamiento de la producción, y estos dos fenómenos fueron consecuencia de la introducción de nuevas rotaciones, de la sustitución del policultivo por una especialización creciente, de la utilización de maquinarias y abonos y de otra serie de importantes mejoras técnicas ${ }^{5}$.

\subsection{LA CRISIS EN ESPAÑA}

España, al igual que el resto de los países europeos meridionales, también se vio afectada por la crisis agrícola de final de siglo. Mientras que en Francia y Portugal la crisis se dejó sentir a partir de la década de 1870-1880, en Italia y España la depresión se retrasó, no manifestándose claramente hasta el decenio 1880-1890.

Estudiaré los efectos de la crisis sobre los tres cultivos básicos de las economías agrarias mediterráneas: cereal, olivar y vid.

\subsubsection{Cereal}

En la agricultura española cerealera se puede hablar de una expansión de la superficie cultivada hasta 1860 . A dicha expansión le siguió, en los últimos años del siglo, un retroceso de la superficie triguera como consecuencia de la competencia de los países ultramarinos. Tal disminución de la superficie triguera, realizada básicamente en las tierras de peor calidad, produjo una disminución de la producción y un aumento de los rendimientos ${ }^{6}$.

Desde 1849 hasta 1881 , sólo en siete años fue necesario que las importaciones de granos superasen a las exportaciones. Pero a partir de 1892, y hasta 1913, todos los saldos fueron deficitarios ?. Esta masiva introducción de trigo extranjero no implica una insuficiencia en la producción autóctona, sino que era consecuencia tanto de un aumento del consumo como de la creciente oferta de cereales baratos. Las dificultades existentes para vender los productos nacionales provocaron una caída de los precios, así como una baja en los

${ }^{5}$ Garrabou (1975), p. 180.

- Tortella (1985), p. 83.

7 Nadal (1975), p. 68. 
ingresos de los agricultores, lo que en última instancia determinó el abandono del cultivo y el éxodo rural ${ }^{8}$.

La caída de los precios agrarios vino acompañada de un descenso del precio de la tierra que se alquilaba. Como apunta $R$. Robledo ${ }^{9}$, es a partir de 1886 cuando se detiene la subida que los arrendamientos venían experimentando desde mediados de siglo. Entre 1886 y 1890 se produce un declive de la renta $e$ incluso retrasos en hacerla efectiva.

España, como la mayoría de los países mediterráneos, optó por una política proteccionista para hacer frente a la crisis. Los aranceles de 1891 y 1895 , que gravaban el quintal métrico de trigo extranjero en 8 y 10,5 pesetas, respectivamente, estimularon la subida de los precios interiores de los cereales. Ante esta situación, la renta de la tierra inició su recuperación y los agricultores volvieron a incrementar la superficie ${ }^{10}$, lo que permitió un aumento de la producción. Fue a partir de 1923 cuando se consiguieron los primeros excedentes trigueros en la balanza comercial desde 1881 .

\subsubsection{Olivar}

En los países mediterráneos, el sector olivarero también se vio involucrado en la tendencia depresiva de la década de 1870-1880.

Con anterioridad a la crisis, es decir, a mediados del siglo pasado, el sector olivarero español se había caracterizado por una oferta de aceites de baja calidad y por una política de expansión del cultivo, la cual se logró desplazando a las viejas viñas, ocupando zonas marginales y mediante nuevas roturaciones ${ }^{11}$. A partir de los años setenta, en Europa se generalizó el uso del petróleo y se produjo una llegada masiva de aceites vegetales y semillas oleaginosas, los cuales desplazaron al aceite del uso no alimenticio ${ }^{12}$. Todo esto, junto con la dificultad para competir con los aceites franceses e italianos, caldos de mejor calidad, provocó una depreciación del aceite español en los mercados europeos.

Hasta el año 1890, el olivar español sufrió uno de los momentos más críticos de su historia. Pero a partir de dicha fecha, y como consecuencia de la depreciación sufrida por la peseta, las exportaciones se recuperaron significativamente. Desde ese momento el aceite español, en lugar de destinarse al uso industrial, pasó a satisfacer el consumo alimenticio de buena parte de los hogares de ultramar.

- Garrabou (1974), p. 227.

- Robledo (1984), pp. 212 y 213.

${ }^{10}$ GEHR (1983 b), p. 299.

"Bernal (1985), p. 425.

12 Zambrana (1985), p. 306. 
Por lo tanto, y posiblemente a consecuencia de lo anterior, en los postreros años del siglo xIx se inicia una etapa en la que se recuperarán los olivares que con anterioridad habían sido abandonados, se expandirá la superficie, aumentará la productividad y se logrará una cierta mejora en la calidad del caldo ${ }^{13}$.

\subsubsection{Vid}

Francia, país productor de vino por excelencia, resultó filoxerada en 1863. Como consecuencia de este hecho, los comerciantes galos se vieron obligados a importar caldos extranjeros. Esta desgracia francesa supuso un beneficio para naciones como España, Italia y Portugal, ya que en todas ellas se produjo un gran incremento de la superficie de viñedos.

Tanto por razones de proximidad geográfica como de precio, el vino español fue el preferido de los franceses, lo cual determinó que el viñedo de nuestra nación viviera un auge sensacional, gracias, sobre todo, a un tratado hispano-francés que entre 1882 y 1892 redujo al mínimo los aranceles.

Al amparo de esta coyuntura favorable, el viñedo se extendió de una manera más intensa por el litoral mediterráneo y la cuenca del Ebro. Asimismo, fue avanzando hacia la Meseta. Pero el crecimiento de las superficies de viñedos se hizo de manera arbitraria y desaprensiva, sin tener en cuenta dos aspectos importantes. Por un lado, se olvidó de que se trataba de una situación coyuntural y, por lo tanto, no se consideraron las perspectivas reales de mercado del vino español. Por otro, no se tomaron las medidas necesarias para impedir que la plaga entrara en España ${ }^{14}$. Y, naturalmente, la filoxera apareció en nuestro país.

España resultó filoxerada a partir de 1878, fecha en la que la plaga irrumpe en Málaga. Los efectos de la misma fueron tan devastadores como en Francia. Fue a partir de 1892, año en el que coincidieron el apogeo de la filoxera en España, el debilitamiento de la misma en Francia y el final del tratado hispano-francés, cuando el vino español entró en una profunda crisis de la que tardó mucho tiempo en recuperarse ${ }^{15}$.

Mientras Francia estuvo afectada por la plaga filoxérica, tanto España como Italia y Portugal habían conseguido un gran crecimiento de la producción, con precios muy elevados. Pero al recuperarse Francia, y por lo tanto no ser tan fáciles las salidas al mercado, se produjo en el sector una sobreproducción que trajo consigo caída de precios, dificultades de venta, etc.

${ }^{13}$ Zambrana (1985), p. 302.

14 Bernal (1984), p. 289.

is Vicens (1972), p. 590. 
Como prueba de las graves consecuencias que tuvo la filoxera en España baste decir que en 1909, es decir, treinta y un años después del inicio de la misma, la plaga había destruido, en opinión de J. Guisado ${ }^{16}$, el 58,7 por 100 del viñedo de Andalucía occidental, el 94,3 por 100 del de Andalucía oriental y el 98 por 100 del viñedo catalán.

Junto a los tres cultivos básicos de la agricultura mediterránea, a partir de 1870 se inició un intento de diversificación de la producción agraria. En Francia ampliaron su superficie fa patata, la remolacha, los cultivos frutícolas y los hortícolas. En Italia se registrǒ un importante crecimiento de los productos cítricos. En España adquirieron relevancia la remolacha, los frutos secos, los cítricos.

A pesar de este intento de diversificar la producción, en España en 1900 la trilogía mediterránea seguía siendo dominante. Las cifras son elocuentes: el sistema cereal abarcaba el 78 por 100 del total cultivado, mientras que el viñedo y el olivar representaban, respectivamente, el 8 y el 6,7 por 100 de la superficie cultivada ${ }^{17}$.

\section{LA AGRICULTURA MALAGUEÑA A FINALES DEL SIGLO XIX}

El objetivo primordial de este artículo es mostrar cuáles fueron las principales transformaciones habidas en la economía agraria malagueña en los últimos decenios del siglo pasado. La elección de esta provincia como espacio en el que estudiar con detenimiento la crisis agraria finisecular se justifica tanto por la adscripción de los cultivos malagueños más importantes a los característicos de la zona mediterránea como por la relevancia que la literatura otorga a los efectos de la plaga filoxérica en la agricultura malagueña $y$, en fin, a las consecuencias que esta depresión tuvo sobre la incipiente industrialización de la economía andaluza ${ }^{18}$.

La fuente básica utilizada en la realización del presente escrito ha sido el Catastro por masas de cultivo y calidades de terreno realizado en Málaga en el año 1899. Este Catastro, fundado en los planos geométricos del Instituto Geográfico, se llevó a cabo entre 1896 y 1899, además de en Málaga, en las provincias andaluzas de Cádiz, Córdoba, Granada y Sevilla, con el fin de controlar la defraudación en el que entonces era el principal impuesto del sistema fiscal español, la Contribución de Inmuebles, Cultivos y Ganadería.

Quiero hacer la salvedad de que en nuestro estudio no contamos con los datos relativos a los municipios de Antequera y Estepona, desaparecidos del

16 Guisado (1983), p. 182.

17 GEHR (1983 a), p. 204.

18 Lacomba (1980) y Nadal (1972). 
Catastro. Esta ausencia de información ha sido paliada por la suministrada por la Reseña Geográfica y Estadistica de 1888, la cual nos va a permitir no sólo obtener una idea aproximada de la situación agraria de los pueblos anteriormente citados, sino estudiar la evolución de toda la agricultura malagueña durante los últimos veinte años del pasado siglo, al comparar los datos de 1879, proporcionados por dicha Reseña, con los de final de la centuria.

\subsection{Medio natural}

La mediterránea y montañosa provincia de Málaga ocupa 7.276 kilómetros cuadrados, lo que equivale al 8,3 por 100 del territorio andaluz. Los atributos de mediterraneidad y de montañosa no se los aplicamos a Málaga de manera arbitraria. La condición de mediterraneidad resulta evidente no sólo porque los 161 kilómetros de su costa sean bañados por el Mare Nostrum, sino porque su clima pertenece al dominio de los climas templados de la Tierra y, dentro de ellos, al clima mediterráneo ${ }^{19}$. Esto significa que los inviernos son moderados, los veranos cálidos, que hay una fuerte sequía veraniega y un régimen escaso de lluvias, las cuales disminuyen a medida que nos desplazamos hacia el este de la provincia.

El adjetivo de montañosa resulta muy apropiado para la provincia malagueña. Situada en el extremo suroccidental de las cordilleras béticas, Málaga presenta una altura media de casi 500 metros. El 80 por 100 de la superficie provincial se sitúa entre los 200 y 1.000 metros, y el 17,1 por 100 tiene menos de 200 metros de altitud. Sin embargo, sólo el 2 por 100 del territorio supera los 1.000 metros $^{20}$.

De Este a Oeste, la totalidad de la provincia es atravesada por un murallón calizo en forma de arco que, junto a una serie de alineaciones montañosas adosadas a él, divide a Málaga en dos ámbitos diferentes. Al sur de esa espina dorsal, el clima presenta rasgos típicamente mediterráneos, siendo la costa el principal exponente de estas características. Por contra, al norte del arco calizo la influencia costera no se deja sentir, ya que el relieve actúa a modo de pantalla y, por lo tanto, las influencias continentales afectan tanto a las temperaturas como al régimen de lluvias.

Tanto en el extremo oriental de la provincia como en el occidental, las compactas alineaciones montañosas llegan prácticamente hasta la costa, permitiendo exclusivamente la existencia de una estrecha franja costera. En el centro, sin embargo, el murallón no es tan compacto y facilita el paso tanto

\footnotetext{
19 Ferré (1984), p. 57.

20 García Escalona (1978), p. 7.
} 


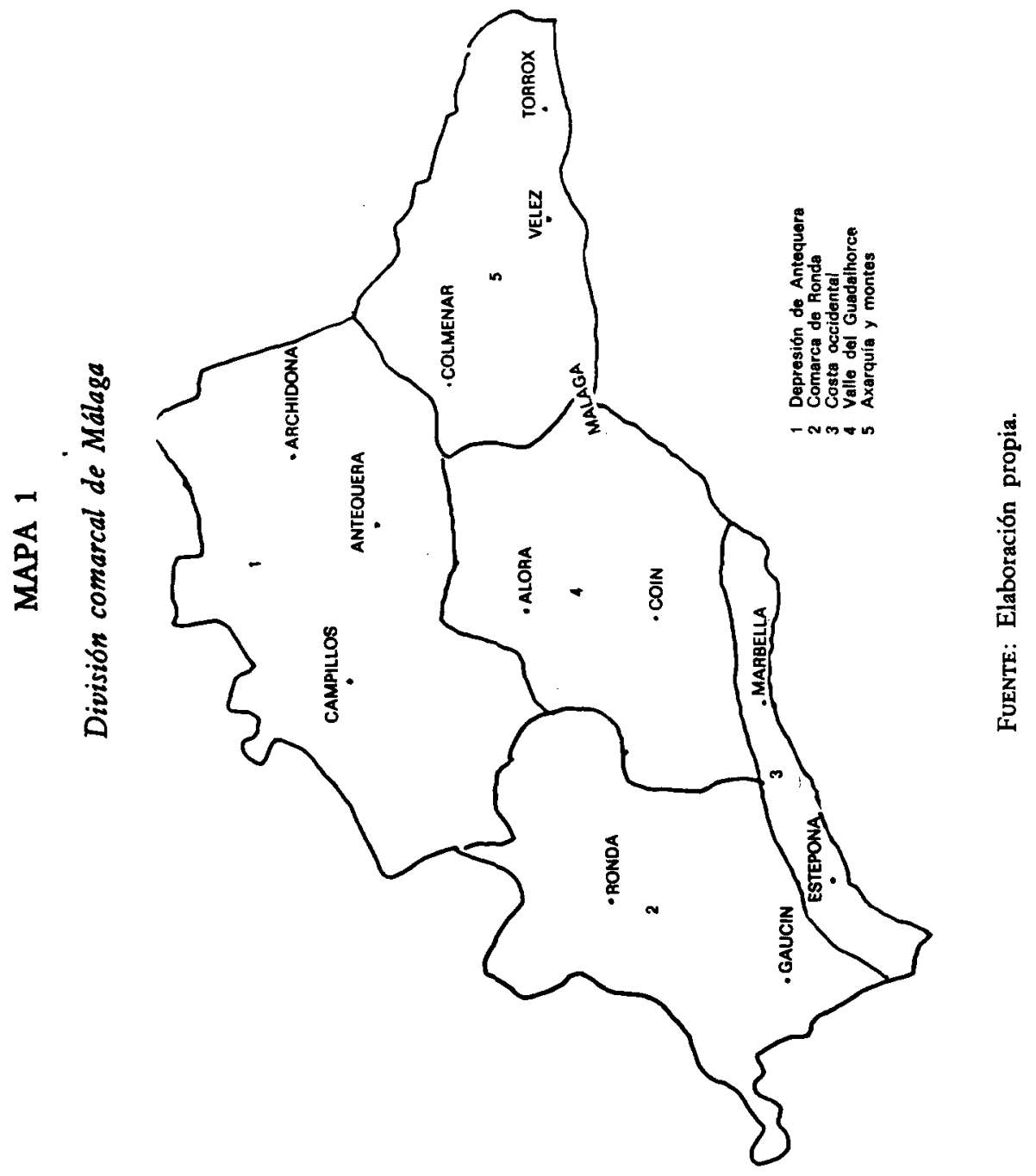


al sector intrabético de Antequera, por el Norte, como hacia la vertiente meridional ${ }^{21}$.

Al oeste de la provincia se encuentra la comarca rondeña, dentro de la cual podemos distinguir dos zonas bien diferenciadas: la serranía y la altiplanicie. La serranía es un complejo conjunto montañoso, con sierras fuertemente erosionadas y estrechos valles con grandes desniveles. La estructura de la propiedad siempre ha presentado un carácter minifundista, y los cultivos más habituales han sido los almendros, los olivares y la vid.

La altiplanicie es una cuenca sedimentaria de altura comprendida entre los 500 y los 800 metros. Es una región especialmente apta para el desarrollo agrícola debido a la riqueza de sus suelos y a su horizontalidad ${ }^{22}$. En la altiplanicie predominan los cereales, los olivares y las grandes explotaciones.

En el extremo occidental de la provincia, y en el espacio comprendido entre la serranía de Ronda y el mar, se extiende una estrecha franja litoral: la costa occidental. Tradicionalmente ha sido una zona donde ha predominado el minifundio y cultivos tales como la vid, la caña, remolacha, etc.

Al este de la provincia, es decir, la región ocupada por los montes de Málaga y la Axarquía, es una gran ladera que se precipita sobre el Mediterráneo. Es un paisaje plagado de barrancos y de pronunciadas pendientes, de las que cuelgan pequeñas poblaciones. Este relieve montañoso hace que la llanura aparezca casi exclusivamente en una franja costera de apenas unos centenares de metros de anchura ${ }^{23}$. El minifundio y el cultivo de la vid han sido característicos de esta región, así como la amplitud de los contrastes climáticos.

Al norte del murallón calizo se encuentra la Depresión de Antequera, la cual muestra un paisaje distinto al sur de la provincia. En ella, los relieves abruptos dejan paso a suaves colinas que, a medida que nos vayamos aproximando al centro, se irán convirtiendo en una llanura ${ }^{24}$. Abierta a las influencias atlánticas, la Depresión es una zona caracterizada por el carácter latifundista de la propiedad de la tierra y por el cultivo del cereal, especialmente al fondo de la llanura, y del olivar.

Se denomina Bajo Valle del río Guadalhorce a una depresión con forma de rombo que es atravesada por dicho río y que se encuentra situada entre la sierra de Mijas y los montes de Málaga ${ }^{25}$. El área que recorre se la conoce también con el nombre de Hoya de Málaga. Es una región estrechamente ligada a la capital y donde el cultivo de regadío ha sido muy importante. Las huertas, los frutales y otros cultivos de regadío forman parte del paisaje de

${ }^{21}$ Ocaña (1984), p. 18.

${ }^{22}$ Gómez Moreno (1984), p. 321.

${ }^{23}$ Justicia (1984), p. 285.

24 Carvajal (1984), p. 341.

${ }^{25}$ Dominguez (1984), p. 263. 
la zona. En las montañas predominan las pequeñas propiedades, mientras que la gran propiedad se da en el fondo del valle.

\subsection{Evolución DE LA AGRICULTURA}

La agricultura malagueña ha sido, y es, típicamente mediterránea. Hacia 1879, la extensión total de la provincia era de 728.512 hectáreas, estando en cultivo unas 450.000 . Lo que preponderaba era el secano, con unas 425.000 hectáreas, y, dentro del mismo, la clásica trilogía mediterránea: cereal, olivar y vid ${ }^{26}$.

\subsubsection{Cereal}

En 1899, el cultivo de cereales y semillas era el más extenso de la provincia, abarcando, probablemente, entre 240.000 y 250.000 hectáreas. Hablo en términos de probabilidad debido a que desconozco la superficie existente en los municipios de Antequera y de Estepona. No obstante, creo no equivocarme, y baso mi afirmación en lo siguiente. Según el Catastro de 1899, la superficie de cereales y semillas era de 199.338 hectáreas, sin tener en cuenta, naturalmente, los dos municipios anteriormente citados. Si para dichos pueblos consideráramos como superficie cerealera la existente en 1879 , es decir, algo más de 50.000 hectáreas, y añadiéramos esa cantidad a la proporcionada por el Catastro, resultaría que a final de siglo los cereales malagueños ocuparían entre 240.000 y 250.000 hectáreas. Viene a corroborar esta afirmación el hecho de que, en 1905, la superficie de cereales en Málaga era de 242.085 hectáreas ${ }^{27}$.

Las especies de cereales y leguminosas que se cultivaban eran trigo, cebada, maíz, garbanzos, habas y guisantes, principalmente. El sistema más generalizado para la producción de cereales y leguminosas era el cultivo extensivo, siendo el cultivo al tercio el sistema de rotación imperante ${ }^{28}$.

En el último año del siglo xIx, los partidos judiciales con un mayor número de hectáreas dedicadas a cereales eran Campillos, con 47.650; Ronda, con 27.815; Archidona, con 25.479; Alora, con 25.051, y, sin lugar a dudas, aunque ignore la cifra exacta, Antequera, en donde en 1879 los cereales abar. caban 56.732 hectáreas.

Al estudiar la evolución de la superficie ocupada por los cereales y semi-

${ }^{26}$ Lacomba (1974), p. 96.

${ }^{27}$ Ministerio de Agricultura (1905), p. 283.

23 Dirección General de Agricultura (1891), p. 367. 
llas a lo largo de los últimos veinte años del siglo pasado, es decir, en un período caracterizado por una fuerte crisis de precios, por un abandono del cultivo y, probablemente, por un descenso de la producción, observamos que en la provincia de Málaga se registró un retroceso de la superficie cerealera total, la cual disminuyó desde las 275.928 hectáreas existentes en 1879 a las poco más de 240.000 que quedaban al final de siglo.

Junto a la disminución experimentada por la superficie de cereales hay un hecho que merece la pena destacar. Si observamos las dos primeras columnas de los cuadros 1 y 2 , podemos comprobar cómo en la mayoría de los partidos judiciales se produjo un incremento del cultivo exclusivo y una reducción en el cultivo asociado. Creo que esto se debió, sin rechazar la posibilidad de un cambio de nomenclatura a la hora de realizar el Catastro, a un abandono del cultivo asociado. Dicho cultivo, en el que el cereal se asociaba prin-

\section{CUADRO 1}

Superficies productivas de la provincia de Málaga. Año 1879 (Hectáreas)

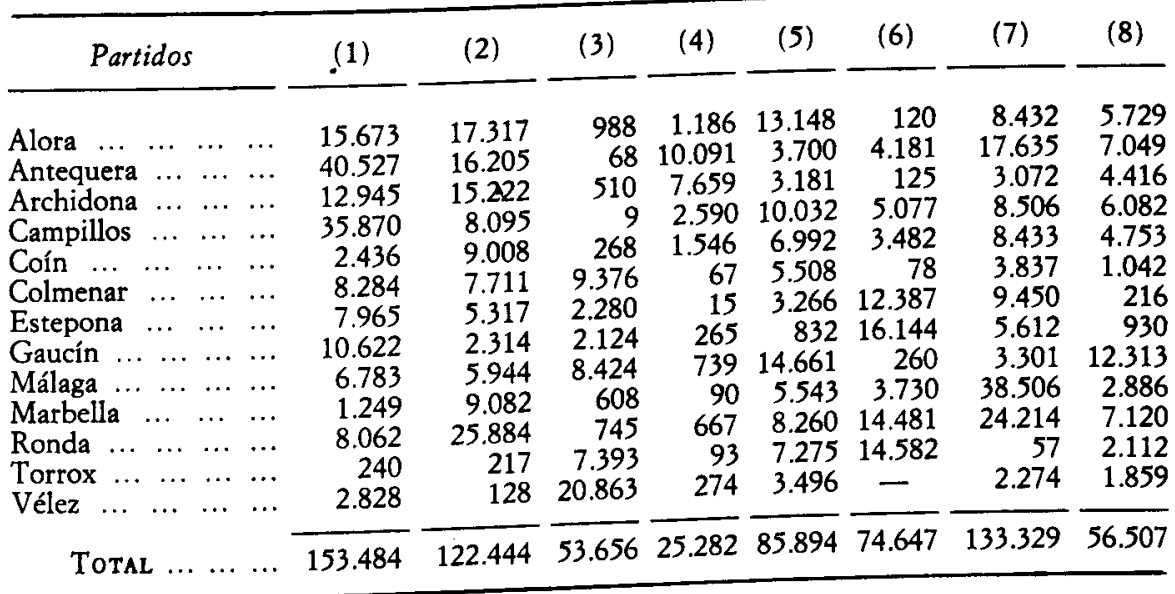

(1) Cereales y semillas.

(2) Cultivo asociado de cereales y semillas.

(3) Viñas.

(4) Olivares.

(5) Cultivo asociado de viñas, olivares, frutales, etc.

(6) Monte alto.

(7) Monte bajo.

(8) Dehesas, alamedas, baldíos con aprovechamiento, etc.

FuENTE: Elaboración propia a partir de la Reseña Geográfica y Estadística de 1888. 


\section{CUADRO 2}

Superfices productivas de la provincia de Málaga. Año 1899 (Hectáreas)

\begin{tabular}{|c|c|c|c|c|c|c|c|c|}
\hline Partidos & (1) & (2) & (3) & (4) & (5) & (6) & (7) & (8) \\
\hline $\begin{array}{lllll}\text { Alora } & \ldots & \ldots & \ldots & \ldots \\
\text { Antequera } & \star & \ldots & \ldots \\
\text { Archidona } & \ldots & \ldots & \ldots \\
\text { Campillos } & \ldots & \ldots & \ldots \\
\text { Coín } & \ldots & \ldots & \ldots & \ldots \\
\text { Colmenar } & \ldots & \ldots & \ldots \\
\text { Estepona } & \star & \ldots & \ldots & \ldots \\
\text { Gaucin } & \ldots & \ldots & \ldots & \ldots \\
\text { Málaga } & \ldots & \ldots & \ldots & \ldots \\
\text { Marbella } & \ldots & \ldots & \ldots \\
\text { Ronda } & \ldots & \ldots & \ldots & \ldots \\
\text { Rondrox } & \ldots & \ldots & \ldots & \ldots \\
\text { Torrox } & \ldots & \ldots & \ldots & \ldots\end{array}$ & $\begin{array}{r}21.810 \\
7.339 \\
16.796 \\
44.430 \\
4.536 \\
11.351 \\
7.076 \\
8.262 \\
5.621 \\
6.695 \\
26.711 \\
1.164 \\
2.844\end{array}$ & $\begin{array}{r}3.241 \\
358 \\
8.683 \\
3.220 \\
4.161 \\
1.253 \\
2.105 \\
3.304 \\
5.174 \\
1.099 \\
1.104 \\
431 \\
570\end{array}$ & $\begin{array}{l}496 \\
- \\
232 \\
- \\
727 \\
1.016 \\
- \\
- \\
3.054 \\
1.494 \\
159 \\
3.520 \\
3.621\end{array}$ & $\begin{array}{r}4.227 \\
3.741 \\
6.448 \\
5.483 \\
1.693 \\
3.107 \\
771 \\
31 \\
1.439 \\
484 \\
4.660 \\
653 \\
306\end{array}$ & $\begin{array}{l}8.088 \\
5.153 \\
4.039 \\
3.680 \\
5.341 \\
1.556 \\
723 \\
441 \\
4.836 \\
1.852 \\
3.406 \\
2.394 \\
4.922\end{array}$ & $\begin{array}{r}192 \\
918 \\
2.380 \\
2.097 \\
2.604 \\
15 \\
7.872 \\
18.508 \\
136 \\
10.627 \\
16.542 \\
7.581 \\
-\end{array}$ & $\begin{array}{r}\overline{1.902} \\
2.906 \\
1.417 \\
5.555 \\
845 \\
- \\
2.956 \\
514 \\
31.554 \\
10.135 \\
43 \\
-\end{array}$ & $\begin{array}{r}23.693 \\
1.287 \\
7.623 \\
15.291 \\
8.478 \\
16.527 \\
9.552 \\
5.163 \\
30.957 \\
5.133 \\
23.345 \\
16.562 \\
19.506\end{array}$ \\
\hline TotaL * ... ... & & 84.10 & & & & 69.472 & 57.827 & 183.117 \\
\hline
\end{tabular}

* Hay que tener en cuenta que faltan los datos relativos a los municipios de Antequera y Estepona.

(1) Cereales y semillas.

(2) Cultivo asociado de cereales y semillas.

(3) Viñas.

(4) Olivares.

(5) Cultivo asociado de viñas, olivares, frutales, etc.

(6) Monte alto.

(7) Monte bajo.

(8) Dehesas, alamedas, baldios con aprovechamiento, etc.

Fuente: Elaboración propia a partir del Catastro de 1899.

cipalmente con olivos, higueras, encinas, se redujo de una manera importante, pues si en 1879 existían 122.444 hectáreas, a final de siglo apenas quedaban 34.703. Pienso, pues, que los agricultores malagueños optaron por especializarse en el cultivo exclusivo, sobre todo en las tierras de mayores rendimientos. Sirvan de ejemplo los casos de Marbella y Ronda. Dichos partidos judiciales, en donde según el Avance de $1891^{29}$ se obtenían unos rendimientos por hectárea de los más altos de Málaga, fueron dos en los que se produjo un mayor incremento en el cultivo exclusivo. Esta reducción del cultivo

29irección General de Agricultura (1891), p. 385. 


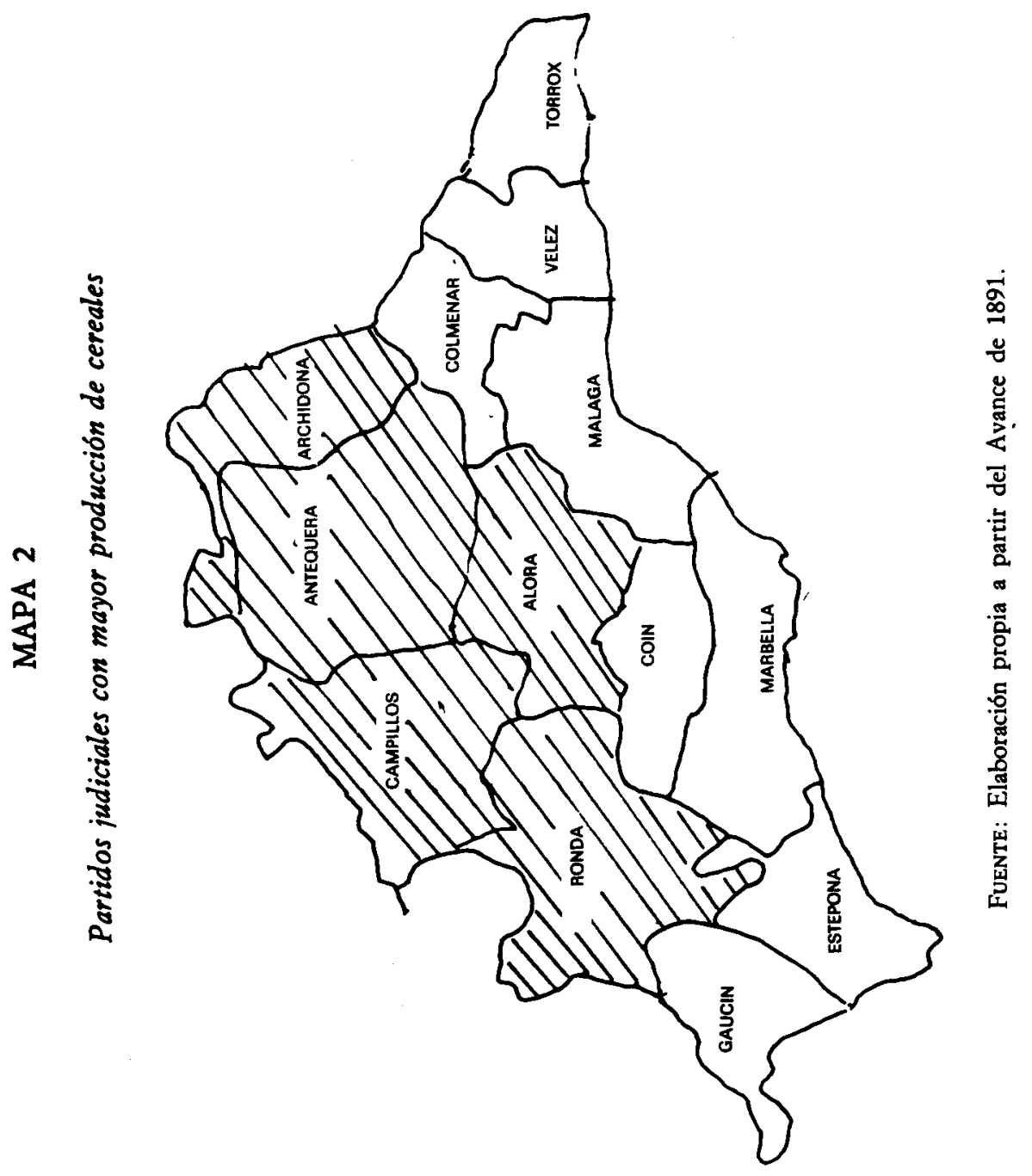


asociado me permite pensar que aunque entre 1879 y 1899 la superficie total de cereales y semillas se redujo, la que quedó estaba mejor aprovechada.

Por lo que respecta a la producción de cereales en la provincia de Málaga, la zona que ostentaba un mayor volumen de producción era la formada por los partidos judiciales de Campillos, Antequera, Ronda, Archidona y Alora.

En cuanto a los rendimientos por unidad de superficie, en el año 1899 se consiguieron en España, por cada hectárea de terreno de trigo, unos rendimientos medios de 7,3 quintales métricos ${ }^{30}$. Utilizando los correctores elegidos por la Junta Consultiva Agronómica, es decir, un hectolitro igual a 0,78 quintales métricos, resulta que la productividad fue de 9,35 hectolitros por hectárea.

En el caso concreto de la provincia de Málaga, los partidos judiciales con un mayor rendimiento por unidad de superficie eran Campillos, Archidona, Marbella y, probablemente, Antequera y Ronda. De los dos últimos partidos citados no puedo dar cifras debido a que en el Catastro de 1899 faltan los datos de algunos municipios, pero no dudo de que los rendimientos conseguidos eran importantes. Quiero hacer una especial referencia al partido judicial de Ronda. Dicho partido ocupa la comarca rondeña, región en la que, como ya dije anteriormente, se pueden distinguir dos zonas muy diferenciadas, la serranía y la altiplanicie. En los municipios de la altiplanicie, es decir, en Ronda, Burgo, Montejaque, Benaoján, Yunquera, los rendimientos por unidad de superficie eran altos. En cambio, en los pueblos de la serranía la productividad de los cereales era muy baja. Esta diferencia de rendimientos dentro de un mismo partido va a provocar, por un lado, que la productividad total del partido sea alta y, por otro, que sea en algunos municipios rondeños donde se consiga la producción media por hectárea más baja de toda la provincia.

Para el trigo, la producción media por hectárea de terreno de primera clase oscilaba entre los 22 hectolitros registrados en los municipios de Cañete la Real y Teba, pertenecientes al partido de Campillos, y los 3,5 hectolitros que se obtenían en Igualeja y Parauta, pueblos enclavados en el partido de Ronda.

Si calculamos la productividad media por cada partido judicial, vemos que el valor más alto se daba en el de Campillos, con 17,5 hectolitros por hectárea de terreno de primera categoría, mientras que el rendimiento medio más bajo era el registrado en los de Alora y Colmenar, situados, respectivamente, en el valle del Guadalhorce y en la Axarquía, con sólo 9,6 hectolitros.

$\mathrm{Si}$ en lugar de considerar solamente los terrenos de primera clase pasamos a tener en cuenta todo tipo de superficies, observamos que la producción

30 Sotilla (1981). 


\section{GRAFICO 1}

Producción media por bectárea de terreno de $1 .^{a}, 2 .^{a}$ y $3 .^{a}$ clases. Trigo

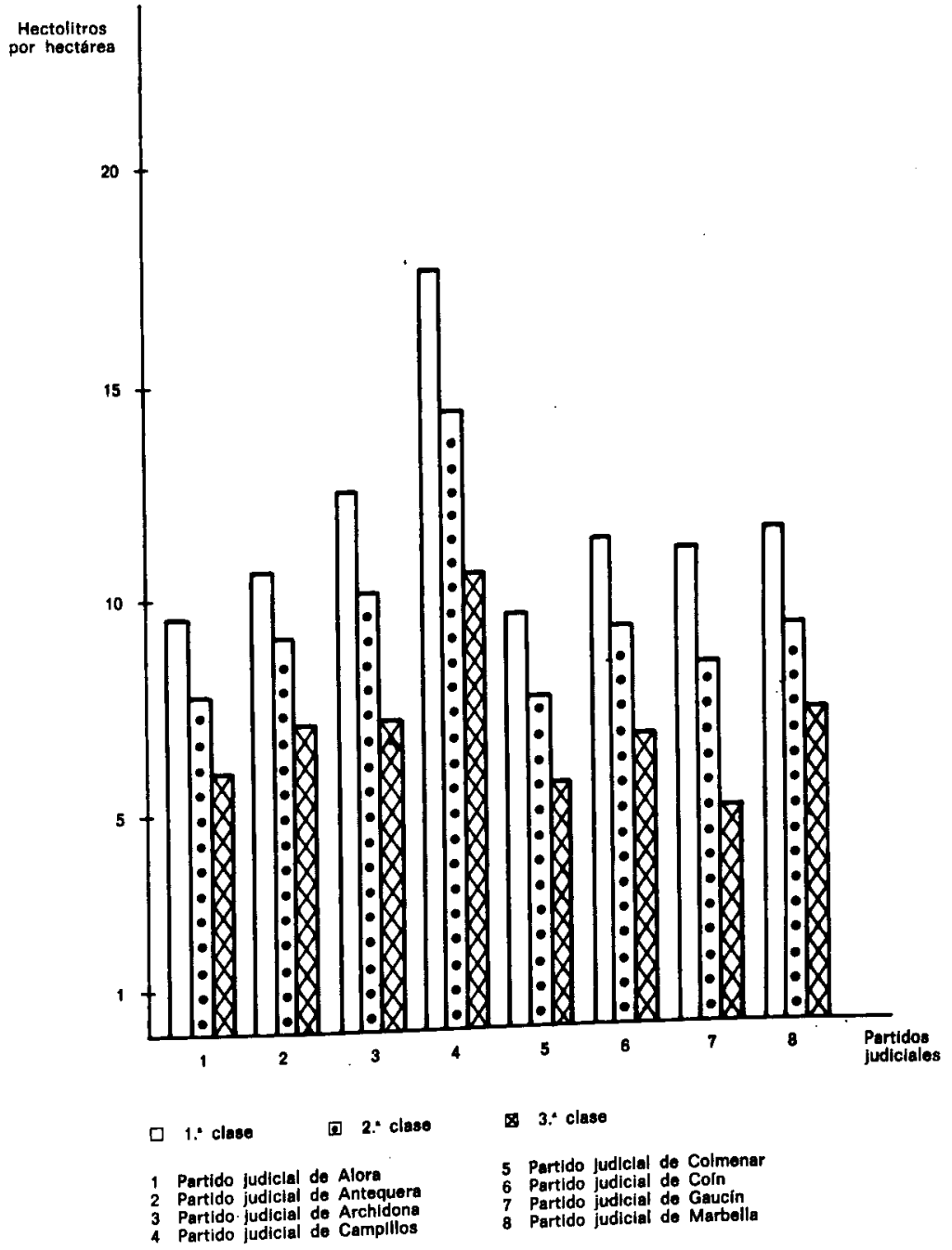

FuENTE: Elaboración propia a partir del Catastro de 1899. 
media por hectárea de terreno de trigo fue, en Málaga, de 8,85 hectolitros, es decir, ligeramente inferior a la conseguida a nivel nacional. Dentro de la provincia, la zona con una mayor productividad era la formada por los partidos judiciales de Campillos y Archidona, situados en la depresión antequerana, con 14 y 9,94 hectolitros, respectivamente. Por contra, en los partidos de Torrox y Vélez, situados ambos en la zona de la Axarquía, sólo se alcanzaban 6,6 y 7,2 hectolitros, respectivamente, siendo los valores más bajos de toda Málaga.

Refiriéndome también al último año del siglo $\mathrm{xIx}$, $\mathrm{y}$ en este caso a la cebada, los rendimientos medios nacionales fueron de 8,38 quintales métricos por hectárea ${ }^{31}$, o, lo que es lo mismo, 13,97 hectolitros $(1 \mathrm{Hl} .=0,6 \mathrm{Qm}$.). En Málaga la productividad fue algo inferior, pues por cada hectárea de terreno se consiguieron 12,48 hectolitros.

Los partidos de Campillos, Ronda y Archidona obtuvieron los mayores rendimientos, siendo en cada caso de 22,16, 14,92 y 14,22 hectolitros, respectivamente.

Si consideramos sólo los terrenos de primera clase, en Málaga la producción media de cebada por hectárea de terreno iba desde los 31 hectolitros de Teba, pueblo del partido de Campillos, hasta los 7 registrados en Júzcar, municipio rondeño. También en este caso era el partido de Campillos el que conseguía unos rendimientos medios superiores, alrededor de 26 hectolitros.

Tanto para el trigo como para la cebada es posible que los datos de rendimientos por unidad de superficie sean superiores a los normalmente conseguidos en la provincia. Creo que esto se debe a que los datos del Catastro probablemente hacen referencia a la cosecha de 1898 , la cual fue extraordinariamente importante.

\subsubsection{Olivar}

A finales del siglo pasado, el olivar ocuparía en Málaga alrededor de 42.000 hectáreas, entre cultivo exclusivo y asociado. Los partidos judiciales con una mayor cantidad de olivares en cultivo exclusivo eran Archidona, con 6.448 hectáreas; Campillos, con 5.483; Ronda, con 4.660; Alora, con 4.227, y, probablemente, ya que desconozco con exactitud la cifra, Antequera. Es lógico suponer que la superficie olivarera antequerana debía de ser muy importante, pues ya en 1879 era el pueblo con mayor terreno dedicado a dicho cultivo en toda la provincia, concretamente 3.991 hectáreas.

En el período de tiempo comprendido entre 1879 y 1899 , la superficie olivarera malagueña permaneció prácticamente estancada. Fueron unos años

${ }^{31}$ Sotilla (1981). 
caracterizados, tal y como vimos con anterioridad, por una crisis en el sector de la que sólo en los últimos años del siglo se inició una ligera reactivación. Málaga registró un fuerte descenso del precio del aceite y sólo a partir de los años 1907-1916 se observó una elevación en el mismo ${ }^{32}$. Por lo tanto, pienso que lo lógico, ante las graves dificultades por las que atravesaba el olivar, era que la superficie se retrajera o, en el mejor de los casos, se estancara, tal y como ocurrió en Málaga. No creo que se produjeran arranques masivos de olivos, sin rechazar la posible existencia de alguno, debido al elevado coste de esa acción. Me inclino a pensar que era más factible abandonar temporalmente el cultivo, lo cual permitía volver a él en un momento coyuntural mejor, que arrancarlo, sobre todo teniendo en cuenta que el olivar necesitaría casi diez años en dar de nuevo frutos.

Del estudio comparativo de las columnas 4 y 5 de los cuadros 1 y 2 podemos extraer las siguientes conclusiones. En 1879, el cultivo exclusivo de olivares suponía 25.282 hectáreas. Por lo que respecta al cultivo asociado de viñas, olivares, frutales, etc., sabemos que ocupaba una extensión de 85.894 hectáreas, de las que 71.651 eran hectáreas de olivares con viñedos y otras plantaciones. De esas 71.651 hectáreas, alrededor de 59.000 eran de viñas; luego el olivar asociado ocuparía aproximadamente unas 13.000. Por lo tanto, y teniendo en cuenta las 25.282 hectáreas de olivos en cultivo extensivo, las 13.000 de cultivo asociado con viñas, frutales, etc., y los posibles olivares asociados a cereales, la superficie total olivarera malagueña rondaría las 40.000 hectáreas.

Para 1899 vemos que la superficie exclusivamente plantada de olivares era superior a la existente en 1879 , habiéndose pasado en estos veinte años de 25.282 hectáreas a 33.043 , sin tener en cuenta los olivos existentes en Antequera y Estepona. Creo que este incremento experimentado en el cultivo exclusivo se debió a un retroceso del cultivo asociado, o bien a que en el $\mathrm{Ca}$ tastro de 1899 se optara por denominar el cultivo de cada zona por el predominante. Es posible también que en el aumento de superficie destinada exclusivamente a olivares influyera de manera decisiva la plaga de la filoxera, ya que con anterioridad a la misma el cultivo asociado de viñas y olivares era muy importante. Al aparecer la plaga y destruir las cepas, los olivos pasaron a ser conceptuados como cultivo exclusivo.

Por lo que respecta al cultivo asociado de olivos, viñas, frutales, etc., en 1899 era de 46.431 hectáreas, de las que 12.141 eran de regadío, 5.054 de viñas y las restantes se repartían entre olivos, higueras y almendros, principalmente.

Creo, por tanto, que si a las 33.043 hectáreas de olivos en cultivo exclu-

${ }^{32}$ GEHR (1981). 
sivo les añadiéramos los olivos en cultivo asociado y los existentes en los municipios de Antequera y Estepona, no nos daría una cifra superior a las 45.000 hectáreas. Viene a apoyar esta afirmación el hecho de que en 1900 la superficie de olivar en Málaga era de 45.003 hectáreas ${ }^{33}$. Estimo, por tanto, que a lo largo de las dos últimas décadas del siglo pasado se produjo un cierto estancamiento en la superficie olivarera de la provincia de Málaga.

Por lo que respecta a los rendimientos por unidad de superficie, en el año 1899 la producción media de aceite por hectárea de terreno de primera clase oscilaba entre los 5,12 hectolitros obtenidos en Jimera de Libar, municipio del partido de Gaucín y enclavado en la serranía de Ronda, y los 1,15 hectolitros registrados en Olías, perteneciente al partido judicial de Málaga.

Calculando la productividad media en cada partido, vemos cómo el rendimiento más alto se daba en Gaucín, con 4,56 hectolitros por hectárea de terreno de primera categoría. Por otro lado, la producción media por hectárea más baja era la existente en Torrox, donde sólo se alcanzaban 2,6 hectolitros.

Si en lugar de tener en cuenta solamente los terrenos de primera clase consideramos todo tipo de superficie, observamos que en el quinquenio 1899. 1903 la producción media por hectárea de terreno fue, en Málaga, de 2,10 hectolitros ${ }^{34}$. Este rendimiento fue superior al conseguido a nivel nacional, donde se lograron 1,74 hectolitros. En la región andaluza, sólo las provincias de Jaén y de Huelva obtuvieron rendimientos superiores a los malagueños, concretamente de 2,45 y de 2,24 hectolitros, respectivamente.

Dentro de la provincia malagueña fueron los partidos judiciales de Gaucín, Marbella y Coín aquellos donde los rendimientos medios por cada hectárea fueron superiores, consiguiéndose, para el año $1899,3,86,3,44$ y 3,13 hectolitros, respectivamente. Por contra, en Torrox y Vélez, al igual que en el caso del trigo, era donde se obtenía una productividad menor, siendo en cada caso de 1,7 y de 2 hectolitros.

Por lo que respecta a la aceituna, los partidos judiciales con una mayor producción han sido tradicionalmente los de Campillos, Antequera, Archidona y Alora. En cuanto a los rendimientos por unidad de superficie, en el último año del siglo pasado fue Alameda, municipio sito en el partido de Archidona, el lugar con una productividad superior, ya que por cada hectárea de terreno de primera categoría se obtuvieron 2.480 kilogramos. En cambio, el rendimiento por hectárea más bajo de toda la provincia se daba en un pueblo del partido de Coín, concretamente en Guaro, donde sólo se alcanzaban 480 ki-

${ }^{33}$ Zambrana (1983).

34 Para la productividad del aceite y de la aceituna, los datos han sido extraídos del Catastro de 1899 y de Zambrana (1983). 


\section{GRAFICO 2}

Producción media por bectárea de terreno de $1 .^{a}, 2 .^{a}$ y $3 .^{a}$ clases. Aceite

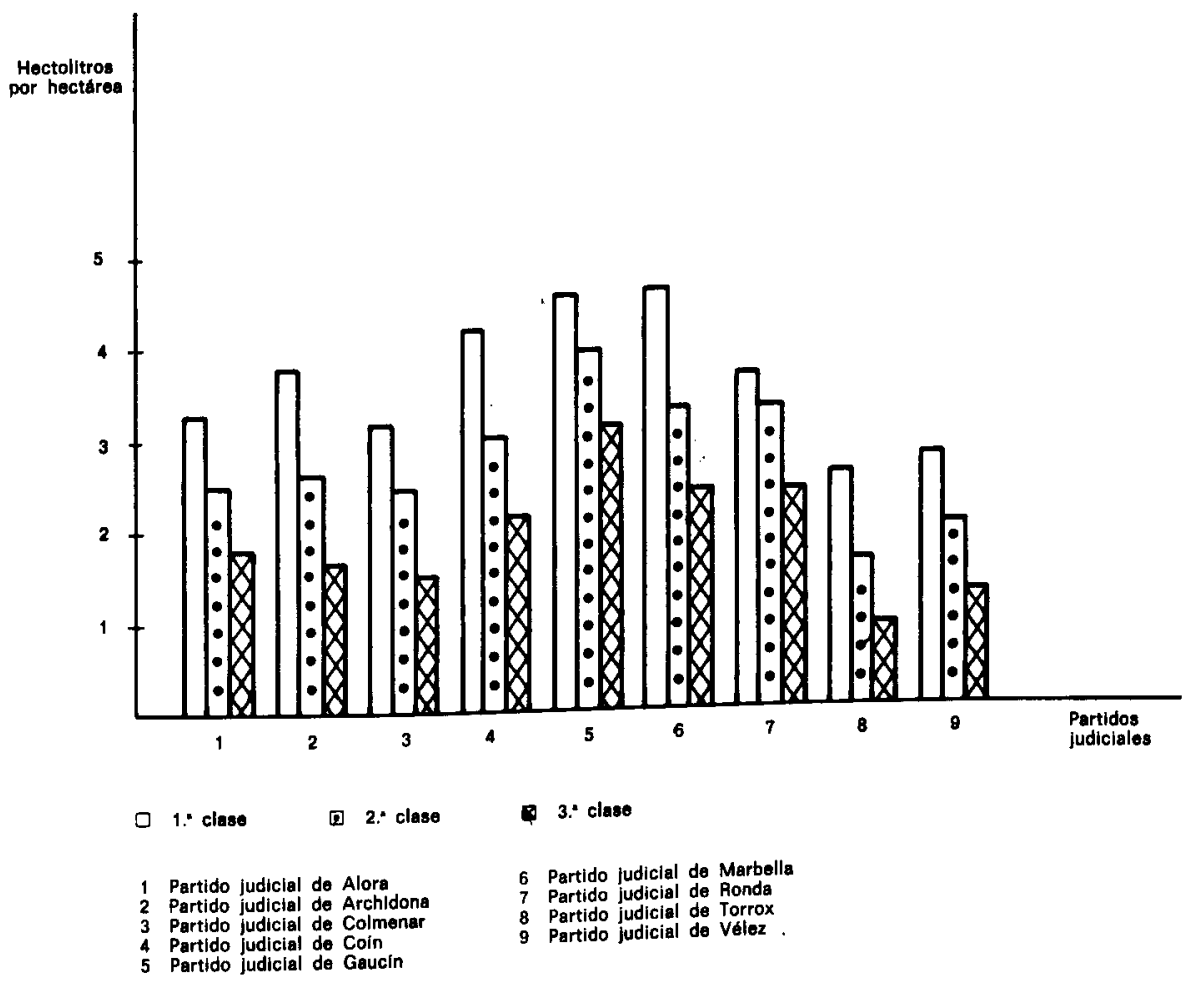

FUENTE: Elaboración propia a partir del Catastro de 1899.

logramos. Dejando a un lado estos valores extremos, la producción media por hectárea de terreno de primera clase rondaba, a nivel provincial, los 1.500 kilos.

Sin hacer distinción en la calidad de la tierra, observamos que en el período 1899-1903 la productividad de aceitunas en España fue de 845 kilogramos. En Málaga, el rendimiento por hectárea fue mayor, lográndose alrededor de 1.160 kilogramos. En Andalucía, este rendimiento sólo fue superado por el conseguido en Huelva, 1.597 kilos. 


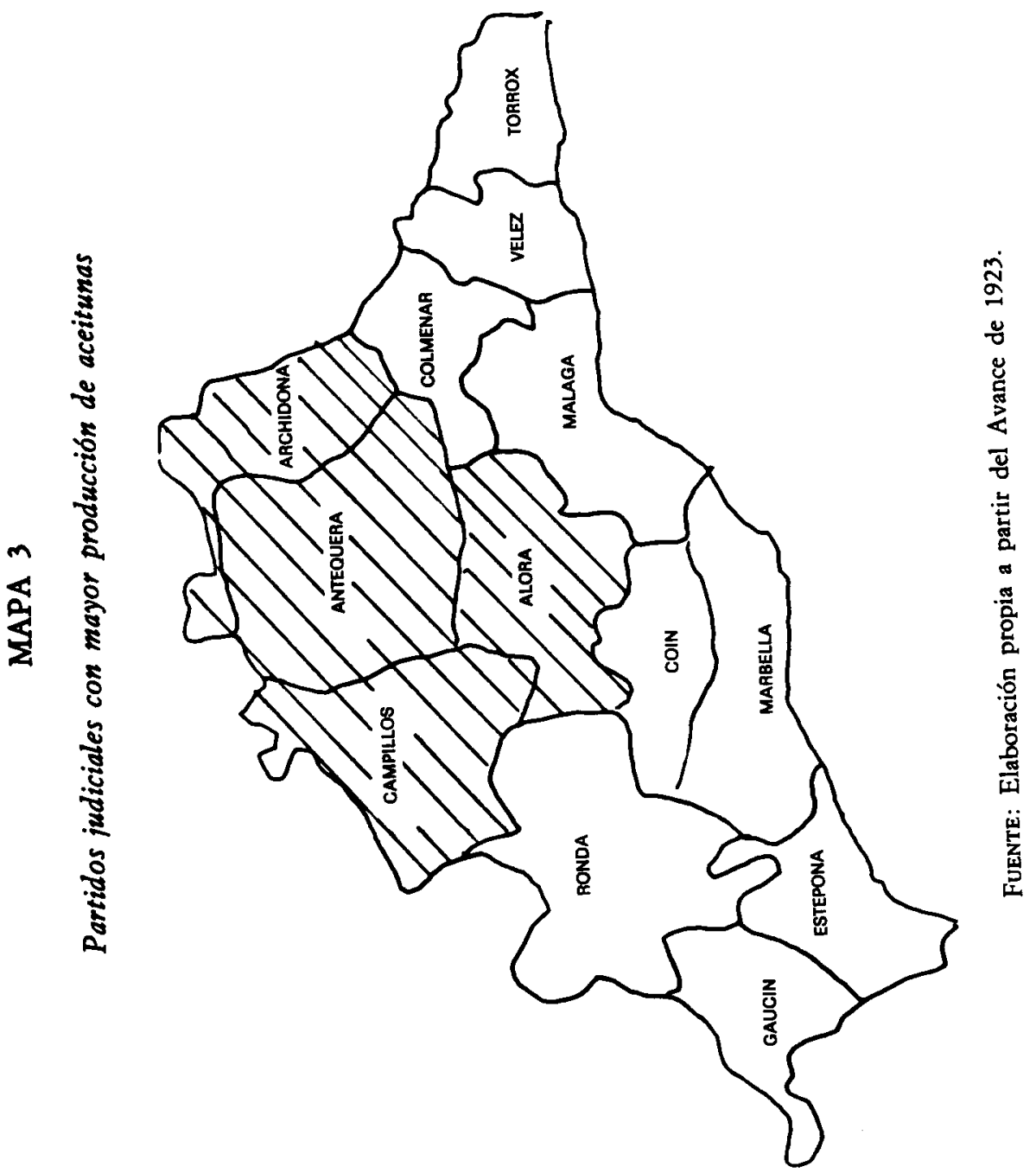




\subsubsection{Vid}

Hacia 1878, la economía agrícola malagueña era predominantemente vitivinícola, extendiéndose las vides por casi toda la provincía. Pero este sector, que llegó a ser el más próspero de la agricultura malagueña, quedó completa y definitivamente desarticulado con la aparición de la filoxera ${ }^{35}$.

Los primeros síntomas de la plaga se detectaron en la finca de La Indiana, en el pueblo de Moclinejo, enclavado en el partido judicial de Málaga. A primeros del mes de agosto de 1878, la superficie invadida alcanzaba 31 hectáreas. A partir de entonces la plaga se extendió, primero de una manera rápida y constante, por toda la zona de la Axarquía y montes de Málaga y, más tarde y algo más lentamente, por la vegà del río Guadalhorce.

Diez años después del primer brote filoxérico, la superficie de viñedos destruida era de 85.303 hectáreas, mientras que la contaminada suponía 18.055. Apenas 10.197 hectáreas estaban libres del insecto ${ }^{36}$.

A final de siglo sólo había unas 20.000 hectáreas de viñedos. De ellas, 12.986 eran viñas de secano, 1.333 lo eran de regadío y 5.054 se encontraban en cultivo asociado con olivares, frutales, etc.

En 1899 , tres partidos judiciales abarcaban el 71,2 por 100 de la superficie provincial de viñedos. Eran Vélez, con 3.621 hectáreas; Torrox, con 3.520, y Málaga, donde había 3.054. Era, pues, en la zona oriental de la provincia donde el cultivo de viñas predominaba claramente.

Estos tres partidos, a pesar de ser los que a final de siglo tenían una mayor superficie de viñas, fueron muy afectados por la plaga filoxérica, perdiendo entre los tres 26.485 hectáreas, sin considerar las cepas en cultivo asociado.

El municipio de Vélez presentaba, en 1899, 10.958 hectáreas de viñedos menos que al inicio de la plaga. También resultaron gravemente afectados Málaga, con 4.348 hectáreas de menos; Colmenar, con 2.207; Canillas de Aceituno, con 2.132, y Arenas, con 2.039. Indudablemente que las disminuciones de superficie registradas en cada pueblo fueron mayores a las señaladas, puesto que los datos anteriores sólo hacen referencia a la superficie dedicada exclusivamente a viñas y no se tiene en cuenta la extensión de cultivo asociado.

Comparando, pues, la situación de las vides malagueñas a final de siglo con la existente al inicio de la plaga de la filoxera, vemos cómo los efectos de la misma fueron muy serios para el campo malagueño. Prueba evidente de la magnitud devastadora de la filoxera es el hecho de que en veinte años se pasara de 112.878 hectáreas a unas 20.000 . Estas últimas eran superficie

${ }^{35}$ Lacomba (1974), p. 97.

36 Carnero (1980), p. 128. 


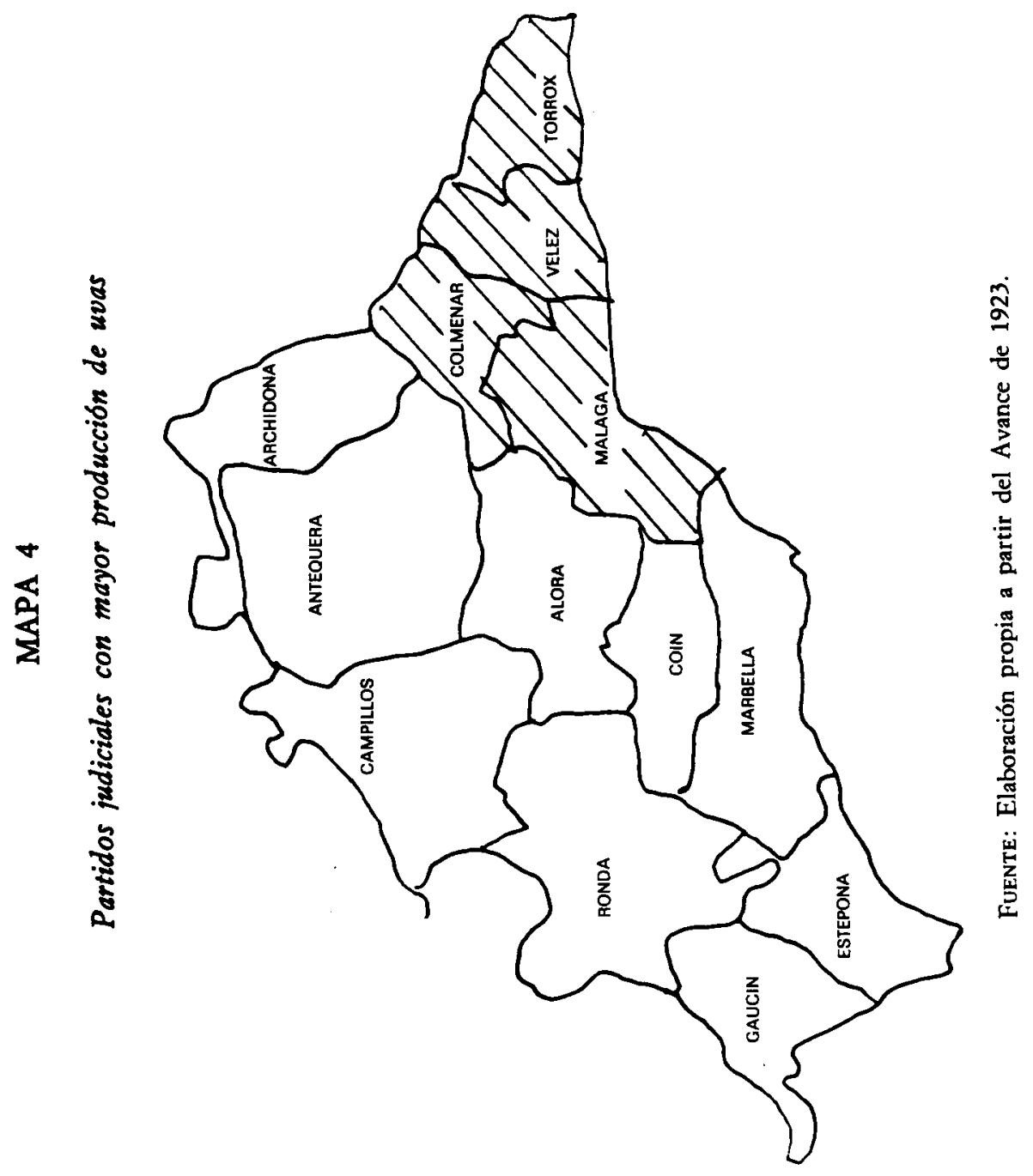


reconstituida, ya que la antigua extensión de 112.878 hectáreas quedó totalmente destruida por la plaga ${ }^{37}$.

Pero la filoxera no se limitó a arrasar el campo, sino que, además, afectó de una manera importante a la estructura socioeconómica malagueña. Sin embargo, y como veremos a continuación, cabe mantener la hipótesis de que con anterioridad a la irrupción de la plaga existiesen ya en el sector vitivinícola de la provincia de Málaga serios problemas, tanto de carácter comercial como de elaboración de los productos. La caída experimentada en la producción a consecuencia de la filoxera vino precedida y acompañada por una pérdida de mercado.

Por lo que respecta al vino de. Málaga, en el año 1872 el cónsul británico en la ciudad afirmaba que el comercio de dicho producto, que en tiempos pasados había sido muy considerable, era desde hacía ya unos años insuficiente debido a la competencia que los vinos italianos y portugueses ejercían en el mercado británico. Además, no veía posibilidades de revitalización de los vinos malagueños ${ }^{38}$.

También el vino de Jerez, tal y como afirma J. Simpson ${ }^{39}$, atravesaba grandes dificultades en su comercio con el Reino Unido, tanto como consecuencia de un cambio en las preferencias, las cuales desde mediados de siglo se dirigían hacia vinos más ligeros y más secos, como por la elevación de los impuestos decretada por el Gobierno británico.

Estos problemas con el mercado británico se mitigaron parcialmente gracias a la llegada de la filoxera a Francia. Para Málaga, dicho suceso supuso una reanimación de la demanda francesa de vinos malagueños $\mathrm{y}$, en general, de vinos exportados por el puerto malacitano.

La pasa de Málaga era otro producto que, años antes de que la filoxera se dejara sentir, presentaba graves problemas por falta de competitividad. Según J. Aguado ${ }^{40}$, antes de la aparición de la plaga los exportadores malagueños ya encontraban serias dificultades para lograr colocar su producto, tanto en Europa, donde el mercado había comenzado a hundirse ya en los años sesenta, como en América, mercado este último que se perdió, principalmente a partir de 1876, a consecuencia del incremento en la producción de pasas de California.

En opinión de J. Morilla ${ }^{41}$, el hundimiento del mercado americano fue tan grande que, a pesar de coincidir con la filoxera, o, lo que es lo mismo,

${ }^{37}$ Ministerio de Fomento (1911), p. 148.

38 British Consular Reports (1872).

39 Simpson (1985), pp. 170 y 171.

40 Aguado (1975), p. 31.

${ }^{41}$ Morilla (1974), p. 86. 
con devastaciones de los viñedos y restricción de la oferta de pasas, provocó una caída de los precios que arruinó totalmente al campesinado.

La historiadora T. Carnero ${ }^{42}$ argumenta, además, que otro factor explicativo de la virulencia destructora alcanzada por la plaga en Málaga fue la escasa capacidad de iniciativa desarrollada por la burguesía vitivinícola malagueña, en contraposición a la actitud de la catalana, tanto a la hora de frenar la invasión y destrucción de los cultivos como en el momento de la replantación. Esta opinión no es compartida por J. Guisado ${ }^{43}$, quien afirma que no hubo grandes diferencias entre las regiones andaluza y catalana a la hora de luchar contra la filoxera. Según dicho autor, fue la vega, una zona constituida por tierras con espesor, agua abundante, fincas relativamente grandes, la región que tuvo un mayor éxito relativo a la hora de la replantación ${ }^{4}$. Esta afirmación parece ser refrendada por el informe que el cónsul británico de Málaga emitió en $1890^{45}$, comentando que eran los propietarios ricos los únicos que habían tenido cierto éxito en la replantación de las vides tras la filoxera.

Nosotros, al estudiar de manera comparada los datos suministrados tanto por la Reseña de 1888 , los cuales hacen referencia a la superficie de viñedos existentes en Málaga en 1879, como por el Catastro de finales de siglo, hemos podido comprobar que los pueblos que forman la vega son prácticamente los únicos que en 1899 presentaban una superficie de viñedos en cultivo exclusivo superior a la existente al inicio de la filoxera, lo que parece apoyar la hipótesis de un éxito en la replantación.

En el éxito alcanzado por la vega a la hora de la replantación influyó notablemente tanto el hecho de que los propietarios de la vega dispusieran de considerables recursos, sobre todo teniendo en cuenta los elevados costes de la replantación, como que el primer patrón de vid americana que se utilizara en la replantación fuera la Riparia. Esta planta dio rápidamente extraordinario resultado en las tierras llanas, pero fracasó de manera estrepitosa en los terrenos montañosos. Esto permitió que en la vega se formaran magníficos plantíos, los cuales producían cosechas más abundantes y de mejor calidad que las obtenidas con anterioridad con las cepas autóctonas ${ }^{* 6}$. Sin embargo, en la zona montañosa de la provincia, dedicada de antiguo a este cultivo, la Riparia no fructificó y fue necesario utilizar otro patrón. El elegido fue el Rupestris de Lot, al igual que en prácticamente toda Andalucía.

Por lo tanto, en Málaga, la filoxera, aun repercutiendo gravemente en If-

${ }^{42}$ Carnero (1980), p. 129.

${ }^{43}$ Guisado (1983), p. 181.

* Guisado (1983), p. 178.

45 British Consular Reports (1890).

* Pancorbo (1901), p. 30. 


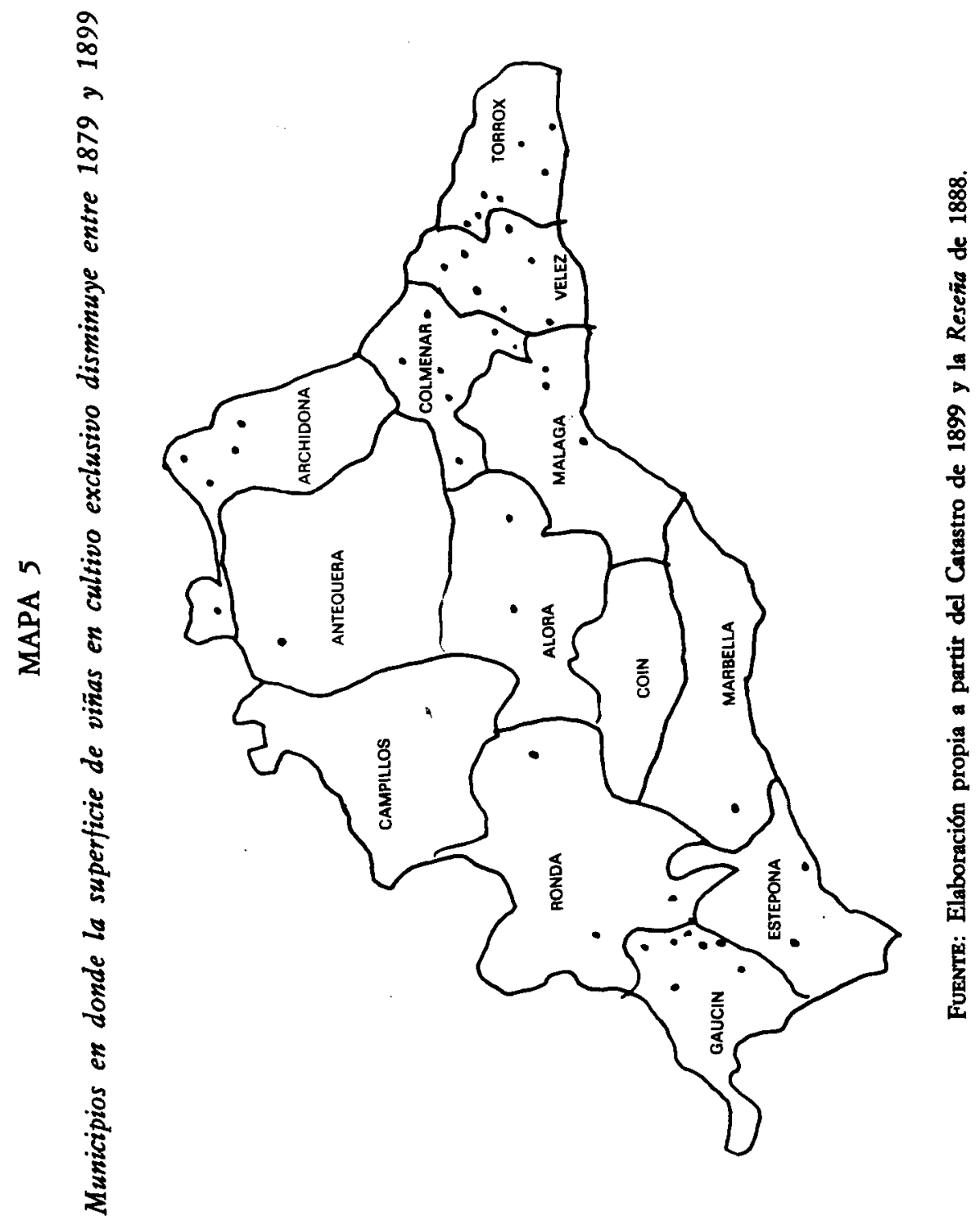




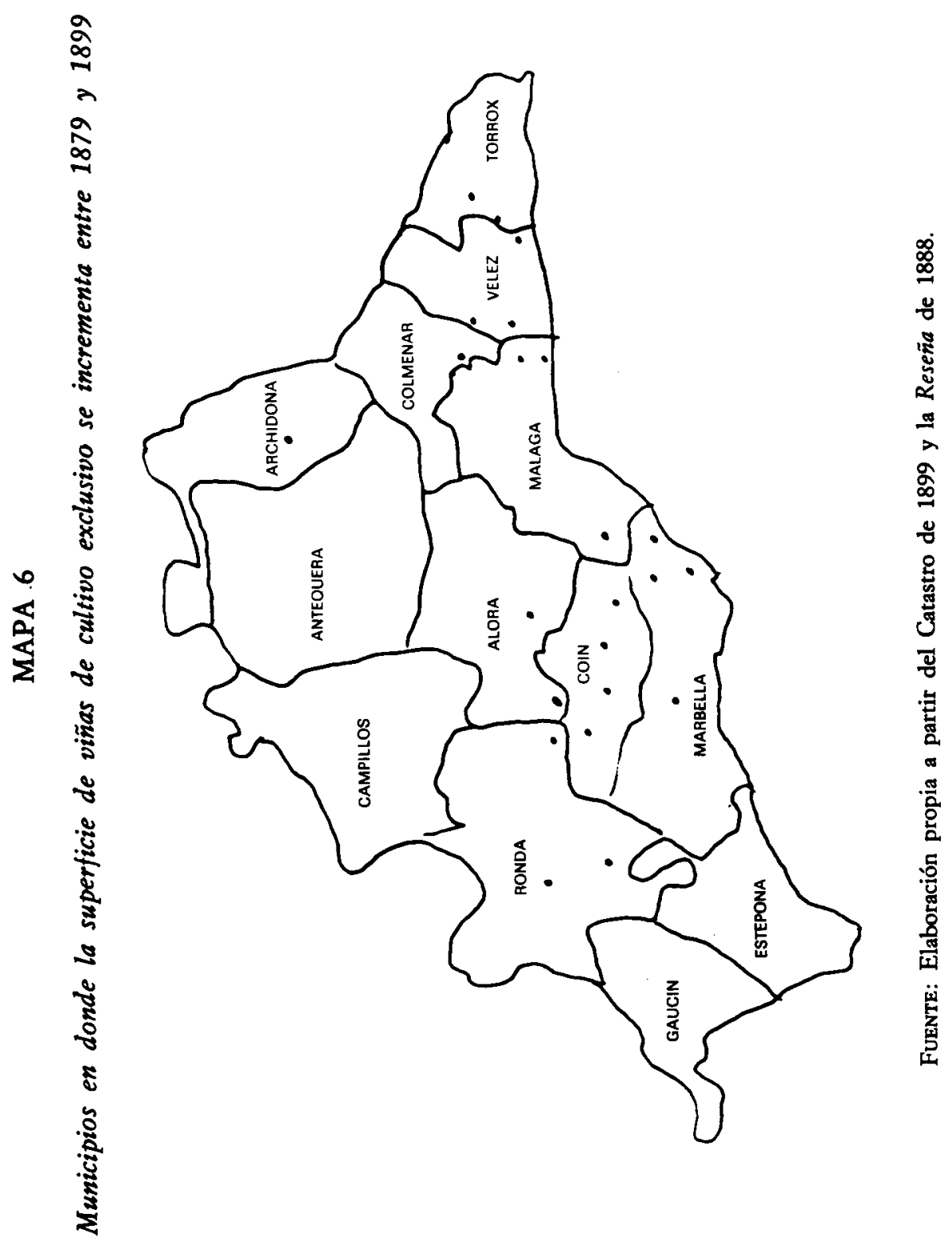


neas generales en toda la provincia, no tuvo los mismos efectos en todas las zonas. La región productora por excelencia, es decir, la formada por la Axarquía y los montes de Málaga, y caracterizada por un carácter minifundista de la propiedad, fue gravemente afectada y la miseria llegó a tal extremo que, en 1894, el Gobierno no repartió ni cobró la contribución debido a la extrema pobreza de sus habitantes ${ }^{47}$. En cambio, en la vega de Málaga, donde las explotaciones eran algo mayores y los propietarios más ricos, los efectos no fueron $\tan$ graves, como lo demuestra el aumento registrado en la superficie de viñas.

A pesar del éxito relativo alcanzado en la vega, lo cierto es que a nivel provincial la economía vitivinícola malagueña no reaccionó de la misma manera como lo hicieron otras. Sirva de ejemplo Jerez, que tras la afectación por la plaga a partir de 1891 consiguió exportar, diez años después, cantidades similares a las de la década de 1880 . Cabe la posibilidad de que la mayor recuperación de la economía de los vinateros jerezanos se debiera a su superior capacidad económica. No debe olvidarse que en Jerez la estructura de la propiedad presentaba caracteres latifundistas, mientras que en la provincia de Málaga, y más concretamente en las zonas donde abundaban los viñedos, el minifundismo era el sistema imperante.

En la provincia de Málaga, y según el estudio de $\mathrm{P}$. Carrión ${ }^{4}$, en el año 1930 , el 96,17 por 100 de las fincas eran menores de 10 hectáreas, y el 71,06 por 100 , inferiores a una hectárea. El número de propietarios con posesiones superiores a las 250 hectáreas era de 479, mientras que 70.114 eran dueños de extensiones inferiores a las 250 hectáreas. En los partidos judiciales de Colmenar, Torrox y Vélez, es decir, la región productora por excelencia, el número de fincas superiores a las 250 hectáreas apenas eran 22.

Como ejemplos ilustrativos del minifundismo existente en las áreas típicas de viñedos, estudiaremos la estructura de la propiedad existente en el año 1919 en los municipios de Colmenar y de Arenas, enclavados ambos en la zona de la Axarquía ${ }^{4}$.

En Colmenar, el 33 por 100 de los propietarios poseían menos de una hectárea, representando éstas superficialmente el 2,44 por 100 del total cultivado. Disfrutando de pequeñas propiedades de una a cinco hectáreas había un 46,5 por 100 de los propietarios, los cuales poseían el 13,17 por 100 de la superficie.

Una estructura muy similar era la existente en Arenas, donde el 87,3 por 100 de los propietarios tenían menos de cinco hectáreas, y el 38,6 por 100 de los mismos poseían menos de una hectárea. Estos últimos eran dueños del

47 Muñoz Cerisola (1894), p. 4.

4 Carrión (1932).

49 Ministerio de Hacienda (1919). 
7,47 por 100 de la superficie, mientras que aquellos que poseían entre una y cinco hectáreas abarcaban el 39,34 por 100 de la extensión total del término.

Es patente, pues, la existencia de una excesiva compartimentación de la tierra. Al pequeño agricultor malagueño, que vio cómo sus cultivos quedaban arrasados, que no pudo acceder a los créditos necesarios para intentar la replantación y que incluso dudó de la operatividad de replantar debido a las grandes dificultades existentes para recuperar los mercados de exportación, no le quedó otra alternativa que la emigración.

En cuanto a la productividad de los viñedos malagueños, en 1899 se podían distinguir dos zonas que, en comparación con el resto de la provincia, presentaban unos valores más altos. Una de ellas era la comprendida por todo el partido de Coín y por los municipios de Mijas, Benalmádena, Pizarra y Yunquera, extendiéndose desde la serranía de Ronda hasta la costa pasando por el valle del Guadalhorce. Hay que subrayar cómo en esta zona se dieron precisamente los casos más claros de sustitución de vides filoxeradas por plantas nuevas.

La otra región, especializada principalmente en las pasas, ocupaba parte de los partidos judiciales de Colmenar, Vélez y Torrox, es decir, la comarca conocida como la Axarquía.

La producción media de vid por hectárea de terreno de primera clase oscilaba entre los 6.066 kilogramos de Alhaurín el Grande, municipio de la vega, y los 1.425 kilos que se obtenían en Sedella, enclavado en la Axarquía. Era en los partidos judiciales de Coín y Marbella donde la vid alcanzaba un rendimiento más alto, con una media superior a los 4.000 kilogramos por hectárea de terreno de primera clase. Considerando toda clase de terrenos, los valores alcanzados en dichos partidos eran de 3.205 y 3.633 kilogramos por hectárea, respectivamente.

También con las pasas eran Marbella y Coín los partidos con una mayor productividad, consiguiéndose una media de 966 y 774 kilogramos por hectárea, respectivamente. Para este producto, el rendimiento más alto era el registrado en el municipio de Fuengirola, perteneciente al partido marbellí, donde por cada hectárea de terreno se obtenían unos 1.316 kilos.

\section{CONCLUSIONES}

Si en España, y en particular en Andalucía, la agricultura sufrió una evidente crisis en el último cuarto del siglo xIx, el caso concreto de Málaga presenta caracteres específicos. Por un lado, la vertiente vitivinícola de la economía agraria malagueña, de importancia relativa indiscutible, experimentó 


\section{GRAFICO 3}

Producción media por bectárea de terreno de $1 .^{a}, 2 .^{a}$ y $3 .^{a}$ clases. Pasas

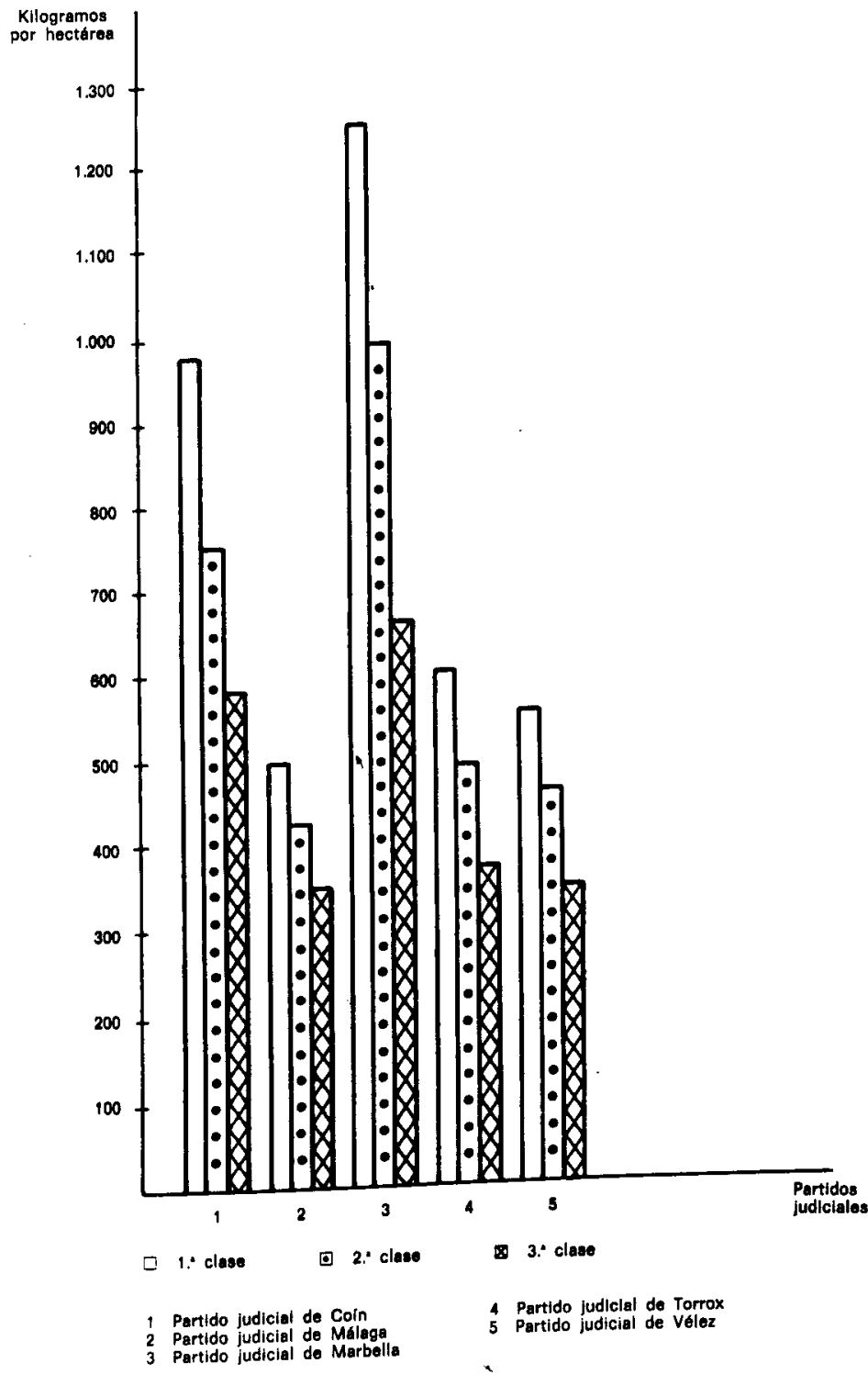

FuENTE: Elaboración propia a partir del Catastro de 1899. 
un proceso de decadencia a raíz de la plaga filoxérica que condicionaría durante largos años la evolución económica de la zona.

Por otro lado, las consecuencias que la depresión finisecular tuvo sobre la economía y la sociedad malagueñas fueron de una excepcional gravedad desde un punto de vista poblacional.

\section{CUADRO 3}

Crecimiento intercensal de la población de la provincia de Málaga (Porcentajes)

\begin{tabular}{|c|c|c|c|}
\hline Partidos & $1877-1887$ & $1888-1897$ & $1898-1900$ \\
\hline 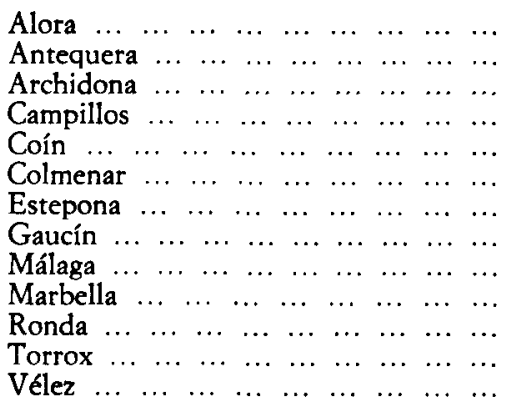 & $\begin{array}{r}8,49 \\
5,77 \\
4,46 \\
5,56 \\
-0,06 \\
-10,26 \\
1,18 \\
0,57 \\
14,65 \\
13,37 \\
-4,13 \\
-9,50 \\
-9,08\end{array}$ & $\begin{array}{l}-9,52 \\
-8,52 \\
-0,78 \\
-1,16 \\
-5,86 \\
-10,36 \\
-10,57 \\
-10,97 \\
-6,30 \\
-11,86 \\
-1,22 \\
-11,59 \\
-3,46\end{array}$ & $\begin{array}{r}0,71 \\
22,62 \\
2,75 \\
6,98 \\
13,10 \\
6,65 \\
4,50 \\
-7,84 \\
4,29 \\
10,35 \\
0,80 \\
5,97 \\
2,23\end{array}$ \\
\hline
\end{tabular}

Fuente: Elaboración propia a partir de los Censos de Población.

\section{CUADRO 4}

Crecimiento intercensal de la población en las provincias andaluzas (Porcentajes)

\begin{tabular}{|c|c|c|c|}
\hline Provincias & 1877.1887 & $1888-1897$ & $1898-1900$ \\
\hline 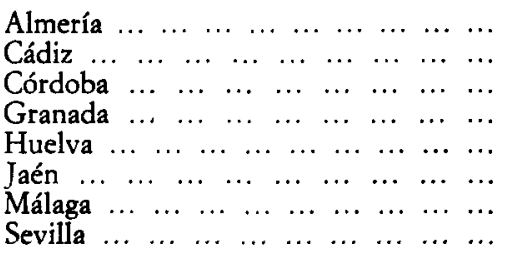 & $\begin{array}{r}2,75 \\
0,15 \\
9,14 \\
1,16 \\
21,09 \\
3,50 \\
3,80 \\
7,49\end{array}$ & $\begin{array}{r}1,56 \\
1,00 \\
5,44 \\
-1,16 \\
0,03 \\
6,45 \\
-6,57 \\
0,54\end{array}$ & $\begin{array}{l}4,12 \\
4,25 \\
2,75 \\
2,80 \\
2,34 \\
1,79 \\
5,51 \\
1,36\end{array}$ \\
\hline
\end{tabular}

Fuente: Elaboración propia a partir de los Censos de Población. 
Entre 1877 y 1887, la población malagueña creció un 3,8 por 100 , pasando de 500.322 habitantes a $519.377^{50}$. Sin embargo, los partidos judiciales de Colmenar, Torrox y Vélez, es decir, aquellos donde el cultivo de la vid era predominante y que por esas fechas ya estaba afectado por la filoxera, registraron disminuciones de población cifradas, respectivamente, en un 10,26, 9,5 y 9,8 por 100. En el período comprendido entre 1887 y 1897, Málaga y Granada fueron las únicas provincias andaluzas que registraron disminuciones de población, siendo en Granada de algo más de un 1 por 100 y en Málaga de un 6,57 por 100. En la provincia malagueña, todos los partidos judiciales tuvieron pérdidas de población, destacando las habidas en Marbella, 11,86 por 100; Torrox, 11,59 por 100; Gaucín, 10,97 por 100; Estepona, 10,57 por 100 , y Colmenar, 10,36 por 100 . Es indudable que la plaga de la filoxera desempeñó un papel muy destacado en el fenómeno de la pérdida poblacional. En la Guía de Málaga de $1894^{51}$ se hablaba de que pasaban de 50.000 los individuos de uno y otro sexo que se habían embarcado para el Brasil, Argentina, Chile y Uruguay. En el trienio 1897-1900, la población malagueña tuvo una cierta recuperación, cifrándose dicha mejoría en un incremento de un 5,51 por 100, siendo este porcentaje el más elevado de los registrados en toda Andalucía. A pesar de ello, en 1900 la población total de la provincia era inferior a la existente en 1887. En ninguna otra provincia andaluza ocurría algo similar.

Málaga fue a lo largo del siglo xIX una economía agrícola mediterránea en la que, al igual que en otras zonas, sus tres cultivos básicos - cereal, olivar $\mathrm{y}$ vid- se vieron inmersos en graves depresiones. En nuestro estudio, y tras comparar los datos de 1879 con los de final de siglo, hemos podido comprobar:

a) Por lo que respecta a los cereales, debemos mencionar dos hechos importantes. En primer lugar, se produjo una cierta reducción de la superficie total provincial $y$, en segundo lugar, hay que destacar el enorme abandono registrado en el cultivo asociado, lo cual parece avalar la hipótesis de una cierta especialización en las tierras de mayores rendimientos. Dado que en dichas tierras aumentó la superficie exclusiva de cereales, puede pensarse que el nivel de producción no disminuyó, pues la mayor productividad de tales zonas pudo compensar el gran descenso experimentado en el cultivo asociado de cereales.

La crisis cerealística no supuso una pérdida económica para los agricultores de las zonas más productivas, pues, como se ha podido comprobar, abandonaron el cultivo asociado y se decidieron por una especialización en el

${ }^{30}$ Elaborado a partir de los Censos de Población.

${ }^{31}$ Muñoz Cerisola (1894), p. 5. 
cultivo. Por lo tanto, a los propietarios de las tierras con-mejores rendimientos, la crisis y la posterior política proteccionista no les afectó de igual forma que a los dueños de las tierras de peor calidad.

b) En cuanto al olivar, parece que hubo un estancamiento de su superficie. Asimismo, debe subrayarse, para evitar posibles errores, el hecho de que antiguos olivos que estaban asociados a viñas pasaron a ser conceptuados en el Catastro de final de siglo como cultivo exclusivo, debido a la desaparición de las cepas como consecuencia de la filoxera.

c) Tras la plaga filoxérica, los viñedos malagueños quedaron prácticamente arrasados, mereciendo la pena destacar el relativo éxito conseguido en la vega a la hora de la replantación de las vides filoxeradas por plantas nuevas. No debe olvidarse el hecho de que el sector vitivinícola malagueño ya atravesaba dificultades comerciales antes de la aparición de la plaga, lo que, sin duda, influyó decisivamente, junto con la escasez de capitales de los pequeños agricultores, en el escaso éxito habido en la sustitución de las vides afectadas por la plaga.

Tras la filoxera las viñas estaban mejor aprovechadas, ya que había aumentado el cultivo exclusivo y se había abandonado el cultivo asociado. Antes de la plaga, el 52 por 100 de las viñas se encontraban en cultivo asociado con olivos, árboles frutales, etc., mientras que al final del siglo ese porcentaje había descendido a un 26 por 100 . Además, los vinateros malagueños habían optado por las pasas en detrimento del vino, y prueba de ello es que la variedad Moscatel, destinada básicamente a pasas, suponía tras la replantación el 74 por 100 del total, mientras que con anterioridad a la plaga representaba el 40 por $100^{52}$.

d) En el período de tiempo estudiado, el erial a pastos se incrementó de una manera importantísima, pasando de 56.507 hectáreas a 183.117 , sin considerar los municipios de Antequera y de Estepona. Este incremento se debió básicamente a antiguas plantaciones de cereales, de viñas y de monte, tanto alto como bajo. Esto es una prueba fehaciente de que la crisis finisecular trajo consigo el empobrecimiento de gran parte de los agricultores malagueños.

Fue en la región oriental de la provincia, es decir, en la zona más afectada por la filoxera, donde el erial aumentó más a lo largo de las dos últimas décadas del siglo pasado. En los partidos judiciales de Colmenar, Vélez y Torrox, la superficie de erial a pastos a final de siglo había aumentado, con respecto a la existente en 1879 , en un 1.486 , un 949 y un 684 por 100, respectivamente.

e) Ante esta deteriorada situación no se reaccionó debidamente, y en ello pareció influir la escasa capacidad demostrada por la burguesía comercial ma-

${ }^{52}$ Ministerio de Fomento (1911), pp. 149 y 150. 


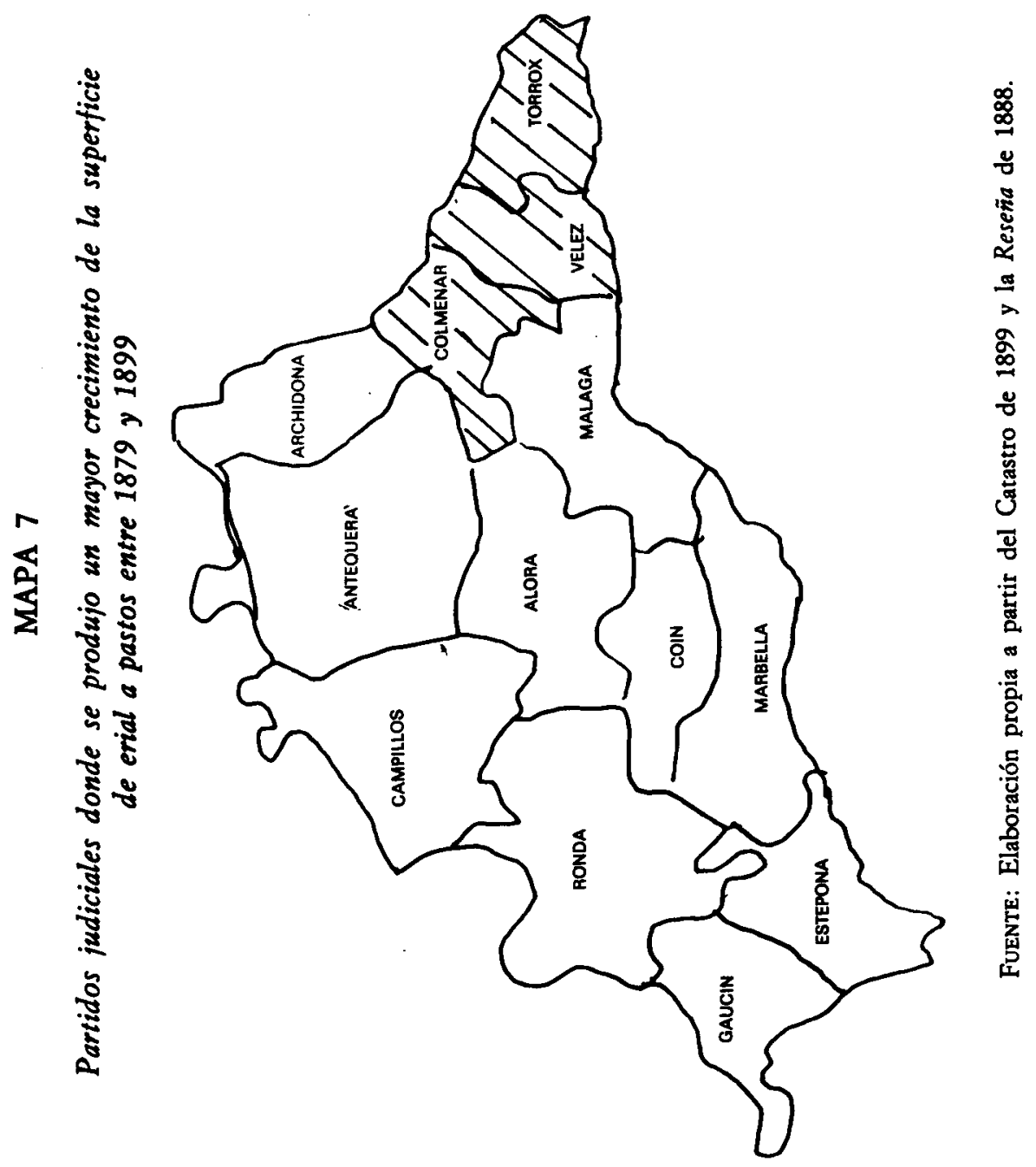


lagueña, así como la debilidad económica de la mayoría de los agricultores, que, a diferencia de los de otras regiones como, por ejemplo, Jerez, eran dueños sólo de pequeñas propiedades. Esto hizo que la agricultura de la provincia de Málaga fuera, dentro de la economía agraria del sur de Europa, y en concreto de la andaluza, una de las que mostrara a finales del siglo pasado signos de mayor pobreza.

f) Por último, significar que en la práctica totalidad de la franja litoral malagueña y en los partidos judiciales de Alora y Coín se dieron con relativo éxito cultivos de cítricos y de caña de azúcar. Para las naranjas y. los limones, la producción media por hectárea de terreno osciló, en 1899, alrededor de los 82.000 y 92.000 frutos, respectivamente; para la caña de azúcar ascendió a poco más de 450 quintales métricos.

La profunda depresión agraria vivida en Málaga repercutió de manera inmediata sobre la demanda y producción de tejidos. A partir de 1885 , tal y como apunta J. Nadal ${ }^{53}$, en Málaga se asistió tanto a un descenso de la producción autóctona como a una disminución en las importaciones de tejidos de algodón, es decir, a una flexión del consumo global de manufacturas algodoneras. Junto a la decadencia de la industria algodonera también se produjo, en los últimos años de la centuria pasada, la crisis de la industria siderúrgica. Málaga vio cómo en 1890-1891 se cerró la antigua ferrería de Heredia, no sólo por motivos técnicos, sino también por una política arancelaria que favorecía a las regiones con recursos carboníferos o próximas -en un sentido comercial, no sólo geográfico- a los yacimientos de carbón mineral.

Parece ser, por tanto, que la crisis dio un golpe definitivo a las esperanzas de industrialización, pues incidió sobre una economía agraria con graves defectos estructurales. Por un lado, la escasa capacidad de ahorro y de demanda de los agricultores minifundistas, mayoritarios en la provincia de Málaga, y, por otro, el bajo nivel salarial de los jornaleros de las zonas latifundistas, principalmente la comarca conocida como Depresión de Antequera. Las respuestas a la crisis, como los intentos de especializarse en ciertos cultivos, así como la replantación de vides en la zona de la vega, además de las medidas proteccionistas, pudieron restaurar la rentabilidad de la agricultura en las zonas de más altos rendimientos $\mathrm{y}$, tal vez, mantener el nivel global de ingresos del sector agrario de la provincia. Sin embargo, tuvieron efectos sociales perniciosos sobre los agricultores minifundistas, como lo prueban el abandono para erial de amplias comarcas y la emigración de altos contingentes de población. Cabe sostener, además, la hipótesis de que la crisis acabara repercutiendo negativamente sobre el nivel de salarios de las zonas de latifundio

${ }^{53}$ Nadal (1972), pp. 69-71. 
que empleaban jornaleros, al convertirse en mano de obra asalariada una parte de los agricultores de minifundio arruinados por la filoxera. Con ello, las perspectivas de crear una demanda densa de productos manufacturados se desvanecieron y las posibilidades de culminar el proceso de industrialización iniciado cincuenta años atrás se alejaron.

Con una agricultura depauperada, con un grave estancamiento demográfico y con el cierre paulatino de los establecimientos industriales, se dio fin a un siglo en el que Málaga, en algún momento, llegó a ser un centro comercial e industrial de relativa prosperidad y con esperanzas de modernización económica.

\section{BIBLIOGRAFIA}

Abel, W. (1973): Crises agraries en Europe (XIII'-XX' siècles), París, Flammarion.

Aguado Santos, J. (1975): «Las exportaciones de pasa en Málaga durante el siglo XIX», Gibraltaro, núm. 27, pp. 23-41.

Bernal, A. M. (1984): «Economía agraria en la Andalucía contemporánea», Papeles de Economía Española, núm. 20, pp. 281-297.

Bernal, A., y Drain, M. (1985): "Progreso y crisis de la agricultura andaluza en el siglo XIX», en Garrabou, R., y Sanz, J. (eds.): Historia agraria de la España contem. poránea. Expansión y' crisis (1850-1900), Barcelona, Crítica, pp. 412-442.

Britis h Consular Reports (1872-1890).

Carnero, T. (1980): Expansión vitícola y atraso agrario, 1870-1900, Madrid, Servicio de Publicaciones Agrarias.

Carvajal, M. C., y Ruiz Sinoga, J. (1984): «La Depresión de Antequera», en varios autores: Málaga, Granada, Andalucía, pp. 339-358.

CARrión, P. (1932): Los latifundios en España, Barcelona, Ariel.

Censos de Población (1877-1900).

D'Angiolini, P. (1969): «L'Italia al termine della crisi agraria della fine del secolo xIX», Nuova Revista Storica, fascs. III-IV.

Dirección General DE Ágricultura, Industria y Comercio (1891): Avance estadístico sobre el cultivo cereal y de leguminosas asociadas en España formado por la Junta Consultiva Agronómica. 1890. Quinquenio de 1886 a 1890, ambos inclusive, Madrid.

Domínguez, Rafael (1984): «El Bajo Valle del Guadalhorce», en varios autores: Málaga, Granada, Andalucía, pp. 261-282.

Ferré Bueno, E. (1984): "Rasgos generales del medio físico de la provincia de Málaga», en varios autores: Málaga, Granada, Andalucía, pp. 35-78.

García Escalona, E. (1978): Memoria del conjunto provincial de Málaga, Madrid, Instituto Geográfico Nacional.

Garrabou, R. (1978): "Transformaciones agrarias durante los siglos XIX y XX», en NA. DAL, J., y Tortella, G. (eds.): Agricultura, comercio colonial y crecimiento económico en la España Contemporánea, Barcelona, Ariel, pp. 206-229.

- (1975): "La crisi agraria espanyola de finals del segle xIX: una etapa del desenvolupament del capitalisme», Reçerques, núm. 5, pp. 163.216.

Garrabou, R., y SANZ, J. (1985): «La agricultura española durante el siglo xix: ¿inmovilismo o cambio?», en Garrabou, R., y SÁnz, J. (eds.): Historia agraria de la España contemporánea. Expansión y crisis (1850-1900), Barcelona, Crítica, pp. 7-191. 
Gómez Moreno, M. L. (1984): «La serranía de Ronda", en varios autores: Málaga, Granada, Andalucía, pp. 317-338.

Grupo Estudios Historia Rural (1981): Los precios del aceite de oliva en España, 1891-1906, Madrid, Servicio de Estudios del Banco de España.

- (1983 a): «Notas sobre la producción agraria española», Revista de Historia EconóMICA, núm. 2, año I, pp. 185-252.

- (1983 b): «Evolución de la superficie cultivada de cereales y leguminosas en España, 1886-1935\%, Agricultura y Sociedad, núm. 29, pp. 285-325.

GuilléN, P. (1973): El imperio alemán, 1871-1918, Barcelona.

Guisado, J. M. (1983): "Crisis agraria e invasión filoxérica en la España del siglo XIX», Revista dE Historia EconómiCA, núm. 2, año I, pp. 165-184.

Instituto Geográfico y Estadístico (1888): Reseña Geográfica y Estadística de España.

Justicia SegoviA, A. (1984): «La Axarquía, los Montes de Málaga y la costa oriental», en varios autores: Niálaga, Granada, Andalucía, pp. 283-316.

LAcombA, J. A. (1974): «En Málaga, a fines del siglo xix: filoxera, desindustrialización y crisis general», Gibralfaro, núm. 26, pp. 91-128.

- (1980): «La filoxera en Málaga», Agricultura y Sociedad, núm. 16, pp. 323-370.

Luzzato, G. (1963): L'economia italiana del 1861 al 1894, Milán, Banca Commerciale.

Malenbaum, W. (1953): The world wheat economy, 1885-1939, Massachusetts, Harvard University Press.

Ministerio de Agricultura, Comercio y Obras Públicas (1905): Prados y pastos. Resumen becho por la Junta Consultiva Agronómica de las memorias sobre dicho tema remitidas por los ingenieros jefes de sección del Servicio Agronómico Nacional, Madrid.

Ministerio de Fomento. Dirección General de Agricultura, Industria y Comercio (1911): La invasión filoxérica en España y estado en 1909 de la reconstitución del viñedo. Resumen becho por la Junta Consultiva Agronómica de las memorias remitidas por los ingenieros del Servicio Agronómico Provincial, Madrid.

Ministerio de Fomento. Dirección General de Agricultura, Minas y Montes (1915): Avance estadístico de la riqueza que en España representa la producción media anual en el decenio de 1903-1912 de cereales y leguminosas, vid y olivo y aprovechamientos diversos derivados de estos cultivos. Resumen becho por la Junta Consultiva Agronómica de las memorias de 1913 remitidas por los ingenieros del Servicio Agronómico Provincial, Madrid.

Ministerio de Fomento. Dirección General de Agricultura y Montes (1923): Avance estadístico de la producción agricola en España. Resumen becho por la Junia Consultiva Agronómica de las memorias de 1922 remitidas por los ingenieros del Servicio Agronómico Provincial, Madrid.

MINISTERIo DE HACIENDA (1919): Servicio de Avance Catastral de la Riqueza Rústica y Recuaxin Mhlaga

Morilla CRITz, J. (1974): «Vid malagueña y vid americana*, Gibralfaro, núm. 26, pp. 69-89.

Muñoz Cerisola, N. (1894): Guía de Málaga. Indicador comercial de España para 1894, Málaga.

NADAL, J. (1972): «Industrialización y desindustrialización del sureste español, 1871-1913», Moneda y Crédito, núm. 120 , pp. 3-80.

- (1975): El fracaso de la revolución industrial en España, 1814-1913, Barcelona, Ariel.

Ocaña Ocaña, M. C. (1984): «Introducción», en varios autores: Málaga, Granada, Andalucía, pp. 17-34.

Orwin, Ch. S., y Whetman, E. H. (1971): History of british agriculture, 1846-1914, Newton Abbot, David and Charles.

PANCORBO, M. (1901): Consideraciones sobre la producción y el comercio de pasas en la provincia de Malaga, Madrid.

Pereira, M. H. (1971): Livre cambio e desenvolvimiento económico. Portugal na segune metade do século XIX, Lisboa, Ediçoes Cosmos. 
PERRY, P. J. (1974): British farming in the great depression, 1870-1914. An bistorical geography, Londres, Newton Abbot, David and Charles.

PRICE, R. (1983): The modernization of rural France, Hutchison University Library.

Robledo, R. (1984): La renta de la tierra en Castilla la Vieja y León, 1836-1913, Madrid, Servicio de Estudios del Banco de España.

Sanz Fernández, J. (1981): "Notas introductorias al libro de Eduardo de la Sotilla "Producción y riqueza agrícola de España en el último decenio del siglo xix y primero del $\mathrm{xx}^{n}{ }_{\star}$, Agricultura $y$ Sociedad, núm. 18, pp. 303-330.

Simpson, J. (1985): «La producción de vinos en Jerez de la Frontera, 1850-1900», en Martín Aceña, P., y Prados, L. (eds.): La nueva bistoria económica en España, Madrid, Tecnos, pp. 166-191.

Sotilla, E. de la (1981): Producción y riqueza agricola de España en el último decenio del siglo XIX y primero del XX, reedición de J. SANZ en Agricultura y Sociedad, núm. 18, pp. 331-409.

Tortella, G. (1981): «La economía española, 1830-1900», en TUÑon de LARA, M. (dir.): Historia de España, vol. VIII, Barcelona, Labor, pp. 11-160.

- (1985): «Producción y productividad agraria, 1830-1930», en SínCHEZ-AlBornoz, N. (comp.): La modernización económica de España, 1830-1930, Madrid, Alianza, pp. 63-88.

Tracy, M. (1964): Agriculture in Western Europe. Crisis and adaptation since 1880, Londres, Jonathan Cape.

Vicens-Vives, J. (1972): Historia económica de España, Barcelona, Vicens-Vives.

Zambrana Pineda, J. F. (1983): La economía oleicola en la España de la Restauración, Málaga (tesis doctoral inédita).

- (1985): “El olivar español, 1870-1930», en Garrabou, R., y SAnz, J. (eds.): Historia agraria de la España contemporánea. Expansión y crisis (1850-1900), Barcelona, Crítica, pp. 301-320. 